\title{
ABST'RACTS AND NOTICES
}

\author{
FROM THE
}

\section{SCIENTIFIC AND TECHNICAL PRESS}

\author{
Issued by the
}

Directorates of Scientific Research \& Technical Development, Air Ministry

(Prepared by R.T.P.)

No. 15. OCTOBER, 1930

\section{Aircraft Design}

Aeronautical Progress, 1914-1930. (R. V. Southwell, Airc. Eng., Vol. II, No. I6, June, 1930, p. 137.) (5.0/13101 Great Britain.)

The author's intimate specialist knowledge and his independence of judgment render this summary of aeronautical progress of value both as an historical appreciation and as an indication of the lines of future advance.

General Survey of German Tendency in Light Aeroplane Construction. (M. Schrenk, Z.V.D.I., Vol. LXXIV, No. II, I5/3/3o, pp. $3^{21-33^{\circ}}$ ) (5.0/1 $3^{102}$ Germany.)

The German light aeroplane has been developed from the glider. A number of rather unorthodox types are thus being built, none of which is produced in any quantity with the exception of the all metal Junkers A.5o. In the Arado L.II, pilot and passenger sit side by side in a roomy cabin with an excellent view, the engine being an inverted Argus. The control column is suspended from above, with great saving in space. The monoplane reaches Ioo m.p.h. with an 80 h.p. engine on a total weight of $\mathrm{I}, 580 \mathrm{lbs}$.

Till recently most German light aeroplanes had foreign engines (Cirrus, Gypsy, Anzani and Salmson), but now have the choice of the Siemens air-cooled radial engines, 5, 7 and 9-cylinder of 80 , 1 10 and 125 h.p. and the Argus already mentioned, on the lines of the British Gypsy.

Minimum Structural Weight of Aeroplanes. (E. Soulages, Rev. Gen. de 1'Aer., No. 12, Dec., I929, pp. I7I-2II.) (5.1/13IO3 France.)

The effect of size on structural weight is broadly considered, in particular the question of a limit of size. The results are plotted in the form of useful load and total weight against surface. A theory of structural weights is also worked out for dirigibles and the ratios of the total weights of the R.100 and L.Z. I 26 are compared with the calculated value with moderate agreement.

Design of Aeroplane Wings. (J. A. Newlin and G. W. Trayer, N.A.C.A., Report No. 345, June, 1930.) (5.102/13104 U.S.A.)

A wing test apparatus of the usual type is shown in a photograph. Ideal curves are established for the relation between breaking load and rib weight, 
and are closely approached by the best designs. In this way certain rules are laid down for proportioning the spacing of the ribs to the depth of the spar, and for various constructional details.

Complete drawings are given of twenty-three wing ribs and of thirty-five types of truss. Test results on these are tabulated.

Metal Aircraft Construction. (Aeroplane (Supplement), Vol. XXXVIII, No. 26, 25/6/30, p. I 209.) (5.1 I/13105, Great Britain.)

Descriptive accounts are given of the forms and methods of construction of steel spars and metal wings, with photographs and sketches, and of methods of engine production with a number of illustrations and specifications. Two performance curves with supercharger are reproduced. Some information is given as to high grade steels, steel tubing and high duty alloys.

Use of Metals in Aircraft Construction. (H. Steudel and G. Bock, Z. Metallk., Vol. XXI, No. 7, July, 1930, pp. 213-223.) (5. I 1/13106 Germany.)

A comparative table is given of the principal properties of aluminium, duralumin, lautal, two types of electron, and two standard German steels. Buckling is discussed and a number of types of corrugated sheet and tube are shown in photographs. The comparative amounts of elastic strain energy are also shown from the point of view of vibrations. The applicability of welding is an important factor in weight saving. Examples of welded and riveted joints are shown in photographs. Corrosion and inflammability are also considered. Photographs of body and wing construction are given in illustration.

Methods of Riveting in Metal Aircraft Construction. (W. Pleines, L.F.F., Vol. VII, No. I, 28/4/30, pp. 1-72, 176th Report of D.V.L.) (5.11/13107 Germany.)

The author has had practical experience of German practice in the Rohrbach Metal Aircraft Construction Co. and in the Junkers Aircraft Factory. Part I of the report gives a comprehensive summary of methods of riveting in use, particularly in German aircraft practice. Some types of punch used in hand riveting in the Junkers works are shown in sketch and photograph where the workmen's hands can reach both sides of the job. Photographs show the position of the workman and sectional sketches give examples of good and bad workmanship. Where only one side of the work is accessible, as in riveting tubes, more special methods are illustrated very fully.

Riveting by machine is discussed and photographs and diagrams of various presses in use are given. In riveting by pneumatic hammer the figure of output is given as $3,000-4,000$ rivets in eight hours against 500-600 rivets by hand hammer.

Optical apparatus for the inspection of rivets in inaccessible positions is described, and photographs are given of the images of the rivet heads as seen in the inspection mirror.

The strength of different types of rivet head is tabulated both for iron and duralumin rivets. Tables of dimensions and weights are also given.

In Part II duralumin rivets in light alloy construction are considered more. particularly. The relative advantages of cold and hot riveting are discussed. The stress distribution is considered and tables of strength are given for different conditions. Figures are also given from English practice.

In Section B of Part II extensive tests on the stresses in the neighbourhood of the rivet hole are described. A large number of photographs is given of opecimens tested to destruction by tearing at the rivet hole and the test figures are tabulated fully. 
Tests were also carried out to determine the best spacing of the rivets, and appropriate rules are laid down.

Twenty-six German references are given and one American.

Horizontal Flight of a Long Range Aeroplane. (J. Vorobeitchik, C.R., 1927, pp. 5I4-5I6.) (5.17/13108 France.)

Starting from the polar equation of the aeroplane, which is expressed in a form that takes aspect ratio into account, an integral expression is found for weight of aeroplane at a given point, and hence for the amount of petrol used up to that point. The time taken is also expressed as an integral and by an application of the calculus of variations a relation is found between distance travelled and the minimum fuel consumption. A certain mathematical precision. is given to the problem, but the practical value is difficult to assess.

Propulsion by Reaction. (M. Roy, Tech. Aeron., Vol. XXI, No. 99, 15/1/30, p. 9.) (5.18/1 3109 France.)

An elementary hydrodynamical theory is given and the disproportionate effect of various assumptions on the calculated efficiency is exhibited numerically and graphically. It is shown that there is little scope for practical application unless possibly for aerial torpedoes at speeds of the order of I,000 kms. per hour.

Simplified Calculations of Static Stresses in Wing Spars. (E. Plath, Z.F.M., Vol. XXI, No. 6, 28/3/30, pp. I38-141.) (5.21/13110 Germany.)

The usual formulæ are plotted in families of curves for different values of the main parameters in such a way that approximate numerical values may be read off rapidly for any combination of dimensions in the practical range. $\bar{A}$ numerical example is worked out.

The Practical Use of Logarithmic Polars for the Calculation of Aeroplane Performance. (G. Bilbault, Tech. Aeron., Vol. XXI, No. Ioo, 15/2/30, pp: 35-4I, No. Ior, I5/3/30, pp. 50-64, No. roz, I5/4/3o, pp. 75-9o, and No. 103, 15/5/30, pp. roo-ro4.) (5.3/131 I I France.)

Polars are plotted on logarithmic scales, and examples show certain advantages for rapid design and performance calculations.

\section{Aerodynamics and Hydrodynamics}

Recuperation of Energy from Trailing Vortices. (M. Pris, Téch. Aer., Vol. XX, No. 98, I5/12/29, pp. 234-245, and Vol. XXI, No. 100, I5/2/30, pp. 32-34.) (5.3/1 $3^{112}$ France.)

Diagrammatic sketches show the disposition of the recuperating blades or screws. The measured efficiencies of the latter are plotted and show sensible increases by recuperation. The author concludes that practically speaking the induced drag can only be diminished by increasing the effective aspect ratio.

Full-Scale Drag Tests on Various Parts of Fairchild (F.C.-2W2) Cabin Monoplane. (W. H. Herrnstein, N.A.C.A. Toch. Note No. 340, May, 1930.) $(5.3 / 13113$ U.S.A. $)$

The zo-foot research tunnel permitted tests on the central part of a full-size Fairchild cabin monoplane. The partial drags investigated were those of the tail surfaces, the engine, the landing gear, the airscrew, and the controls. The effects of adding a turtle back and of opening cabin windows were also observed. The detailed results are given in tables and in charts, and permit a rational analysis of the resistance into its components. 
Wind Resistance of Automobiles. (F. W. Pawlowski, S.A.E., Vol. XXVII, No. I, July, 1930, pp. .5-14.) (5.3/1 $3^{114}$ U.S.A.)

An elementary theory of eddy formation round bodies of various shapes is sketched in two dimensions. Four photographs of motor cars illustrate extremes between bodies with no attempt at fairing and very completely faired bodies. Comparative curves are plotted. Methods of testing and test reduction are considered in a subsequent discussion.

Spread of Vorticity behind a Cylinder. (L. Rosenhead, Proc. Roy. Soc. A.r 27, No. 806; pp. 590 to 612.) (See abstract No. I4/12760.) (5.3/131 5 Great Britain:)

The problem of the stability of Kármán's vortex double row is extended to the case where the cores of the vortices are of finite dimensions. The particular assumption is made that the core is of circular section and uniform vorticity, the motion outside the core being irrotational and cyclic.

In this way the problem is given a physical reality which is absent from most previous discussions.

Kelvin's treatment is reviewed and his methods are shown to be powerful and elegant and to give certain results in the simplest possible manner.

The stability of the double row is then investigated with the necessary modifications of Kármán's and Lamb's analysis.

A lengthy numerical discussion is given of the criterion for stability which is found to exist over a finite range of three-dimensional disturbances:

The Problem of Autorotation. (H. B. Irving, Airc. Eng., Vol. II, No. 16, June, 1930, p. I42.) (5.315/13116 Great Britain.)

The subject is dealt with from the point of view of aeroplane stability. The variety of the devices applied gives some indication of the complexity of the aerodynamical problem.s involved. A large amount of numerical data is embodied in a graphical chart, chiefly from model results, but partly also from fullscale tests.

A list of 13 British and two American references is given. No reference is made to the extensive German literature which, however, largely covers the same ground.

Flow and Force Equations for a Body Revolving in a Fluid. (A. F. Zahm, N.A.C.A. Report No. 323, March, 1930.) (5.316/131 7 U.S.A.)

A development of the theory of airship hulls in curvilinear flight.

Part I gives a general method for finding the steady flow velocity round a body in plane curvilinear motion, whence the pressure is found by Bernoulli's energy principle. Integration of the pressure supplies basic formulæ for the zonal forces and moments on the revolving body.

Part II, applying this steady flow method, finds the velocity and pressure at all points of the flow inside and outside an ellipsoid and some of its limiting forms, and graphs those quantities for the latter forms. In some useful cases experimental pressures are plotted for comparison with theoretical.

Part III finds the pressure, and thence the zonal force and moment, on hulls in plane curvilinear flight.

Part IV derives general equations for the resultant fluid forces and moments on trisymmetrical bodies moving through a perfect fluid, and in some cases compares the moment values with those found for bodies moving in air.

Part $V$ furnishes ready formulæ for potential coefficients and inertia coefficients for an ellipsoid and its limiting forms. Thence are derived tables giving numerical values of those coefficients for a comprehensive range of shapes. 
Measurement of Distribution of Vortices behind Obstacles. (E. Tyler, Phil. Mag., No. 6I, June, 1930, p. III3.) (5.32/I3118 Great Britain.)

Two electrically heated platinum wires $2.5 \mathrm{~cm}$. long and $2.5 \times 10^{-4} \mathrm{~cm}$. diameter with constant heating currents form part of two similar electric circuits each coupled to the grid input circuit of a five-valve amplifier by means of separate primaries of a transformer. A diagram of connections gives further details. The object of the amplifier is to increase the sensitivity of the readings. in determining the distribution of vortices in a stream behind an obstacle by observing the velocity fuctuations at frequencies of $\mathrm{I} / \mathrm{I} 00 \mathrm{sec}$. and upwards. Numerous numerical results obtained by this improved apparatus are tabulated and shown graphically. There is substantial agreement with the work of other experimenters, but the numerous anomalies in the hydrodynamical aspect of the subject remain unexplained.

Summary of Hydrodynamic Theory. (D. Riabouchinsky, Bull. Tech., No. 67, Feb., 1930, 72 pp.) (5.32/13119 France.)

In Chapters I and II an illustrated exposition is given of a number of solved problems in the motion of a perfect incompressitule flufict. In Chapter III the question of the influence of compressibility is introduced and applied to waves of expansion. Finally, the resistance of air at high velocities is considered, particularly with reference to the flight of a bullet or projectile and a semiempirical formula is derived which with certain adjustments fits experimentaI values closely.

Instability of a Fluid Heated Below. (H. Jeffreys, Proc. Cam. Phil, Soc., Vol. XXVI, Pt. 2, Apl., 1930, p. I 7o.) (5.32/13120 Great Britain.)

The case of an incompressible fluid has been dealt with previously by the author. Additional terms are now introduced to take account of compressibility, and to the approximations used it is found sufficient to replace the temperaturegradient by the difference between temperature gradient and adiabatic gradient. This is the assumption usually made, and it is satisfactory to have a formal demanstrațion of its validity.

The Added Mass of Prisms Floating in Water. (A. D. Brown, E. B. Moullin and A. J. Perkins, Proc. Cam. Phil. Soc., Vol. XXVI, Pt. 2, April, I930, p. 258.) (5.32/13 121 Great Britain,

The free simple harmonic oscillations of a floating body in a vertical plane depend on the virtual mass, i.e., the mass of the body plus the effective added mass of the moving fluid. Approximate expressions are developed and the calculations are compared with experimental determinations, the latter being systematically slightly less than the former.

The Magnus Effect. (H. Blenk (reply to F. Ahlborn. See abstract No. I4/12770', Z.F.M., Vol. XXI, No. 3, 14/2/30, p. 66.) (5.32/1 3122 Germany.) steamer.

The rotor ship is defended as competitor of the sailing ship, not of the screw

Flight Tests of Aeroplanes. (A. Toussaint, Rev. Gen. de l'Aer., No. 12, Dec., 1929, pp. I to Ior.) (5.322/13123 France.)

A systematic scheme of flight tests is laid down. The instruments and instrumental measurements are discussed and typical test results are plotted critically. Comparisons with model tests are also made. 
Six Component Measurements on a Junkers A.35 Model at Göttingen. (H. Blenk, L.F.F., Vol. VI, No. 5, 22/3/30, pp. 156-162, 175th Report of D.V.L.) (5.323/r3124 Germany.)

Dimensioned sketches of plan, front and side elevation are given, and a perspective sketch defines the system of co-ordinates used. Polars are given for wing alone and for complete model from $-20^{\circ}$ to $180^{\circ}$, for different elevator settings and for model without carriage.

Yawing moments are given against angle of yaw for different settings of rudder elevator and ailerons.

The model tests were made without airscrew; measurements with airscrew will follow.

The Best Bracing Point for Monoplane Wing Spars. (R. Vogt, Z.F.M., Vol. XXI, No. 2, 28/1/30, pp. 29-35.) (5.337/133125 Germany.)

Elementary expressions are found for the fibre stresses arising from bending moments, shearing forces and axial loads, for a set of five different bracing points. The total fibre stress is found by addition and plotted, to determine the minimum graphically.

The built-in monoplane spar shows little advantage over the pivoted spar.

The hiplane has an advantage of about 16 per cent. in weight of spar and of bracing members. The best point of attachment appears to be at about 60 per cent. of the half span from the centre line, almost independently of the type of construction.

Note on the Wings of Gliding Birds. (G. T. Walker, Jrnl. Roy. Aer. Soc., Vol. XXXIV, No. 234, June, 1930, p. 495.) (5.37/13126 Great Britain.)

Ten sketches are given of the wings of vultures in fight.

\section{Airscrews}

Experiments on Airscrews in an Oblique Stream. (O. Flachsbart and G: Krober, Z.F.M., Vol. XX, No. 23, 14/12/29, pp. 605-614.) (5.42/13127 Germany.)

Two modeis were tested, one with constant chord pitch 0.5 , the other with pitch, constant over the outer part of the blade, c.2.

Details of the driving motor and of the mounting in the wind channel are given.

Two systems of axes are defined diagrammatically, one fixed with respect to the relative wind, the other with respect to the airserew axis.

There are three coefficients of force, three of moment for each system, twelve coefficients in all. There are two independent variables, $\lambda=$ relative wind/tip. speed and $a=$ incidence of the axis to wind. The twelve coefficients as determined experimentally are plotted with respect to a for different constant values of $\lambda$, and with respect to $\lambda$ for different constant values of $a$.

The results are exhibited graphically in 20 charts, each showing a family of curves. Generally speaking, up to $15^{\circ}$ axial inclination there is a comparatively small change in the axial thrust and moment, but appreciable side forces and moments come into existence.

Above $15^{\circ}$ axial incidence the curves become heavily distorted.

The same remarks apply to the efficiency, which is shown in four separate charts. A preliminary chart exhibits the effect of the mounting which is comparable with the effects of $15^{\circ}$ axial incidence.

The whole series gives information of great practical importance. 
Resonance Vibrations in Airscrews. (F. Liebers, L.F.F., Vol. VII, No. 3, I6/5/30, pp. I $37^{-1} 5^{2}$, I82nd Report of the D.V.L.) (5.461/1 $3^{\text {I } 28 \text { Germany.) }}$

The author surveys every possible source of airserew vibrations in resonance and concludes that irregular engine impulses are the only serious factor.

Air forces set up by vibration are of little importance. Their frequency is much larger than the frequency of rotation, so that the danger of resonance cannot arise from this source.

Modes of vibration of an airscrew are considered and it is found that the bending stiffness, the diameter of the hub and the inertia forces of rotation are the numerically important factors.

The frequency of the bending oscillations of an airscrew blade under the influence of rotational inertia forces appears to be of the same order as the engine frequency and is determined by Rayleigh's principle of the minimum natural frequency of an elastic system. This gives an upper limit.

Another rule for the frequencies of an elastic system under several systems of forces (in the present case elastic forces and inertia forces) yields a lower limit.

The upper and lower limits are so close as to determine the bending frequency under rotational inertia forces with sufficient accuracy for practical purposes.

A simple formula involving only the angular velocity of the airscrew, the natural period at standstill and the ratio of hub radius to blade length gives the natural period of bending oscillations in rotation to a sufficient approximation, and in a still simpler form gives a lower limit. The latter formula is valid for a wide range of types of blade and mounting.

In particular it appears from the formula that a relatively large hub diameter increases the natural period, as is desirable. A number of numerical examples are worked out and the results are exhibited graphically.

Material for Airscrews. (F. Seewald, Z. Metallk., Vol. XXI, NG. 7, July, I93o, pp. 227-230.) (5.49/1 3129 Germany.)

The application of metal to the construction of airscrew blades is discussed and illustrated by six photographs of blades in steel and light alloys:

\section{Undercarriages, Etc.}

Design and Tests of Wheels and Shock Absorbers for Landing Carriages. ( $\mathrm{H}$. Landwerlin and L. Suard, Bull. Tech., No. 65, Jan., 1930, 33 pp.) (5.51/13130 France:)

The forces on the landing carriage transmitted from the point of contact of the wheels to the aircraft are discussed systematically and the results of static tests of separate parts are plotted and tabulated. The mechanical details are also tabulated. The systematic design of a range of wheels is considered, in particular the stresses on the wheel and the overhang of the axle. The qualities of pneumatic wheels and shock absotbers are discussed mathematically and experimentally.

Oleo Pneumatic Shock Absorber for Aeroplanes. (Engineering, Vol. CXXIX, No. $3357,16 / 5 / 3^{\circ}$, p. 647.$) \quad\left(5.5^{1} / 3^{1} 3^{\text {I Great Britain.) }}\right.$

General arrangement and load deflection diagrams are given, showing an increase of the total strut load from $2 \frac{1}{2}$ times to $3 \frac{3}{4}$ times normal load. A working pressure of $85^{\circ} \mathrm{lbs}$. per sq. in. is given, requiring to be pumped up at intervals of six months. The weights are not stated. 
Shock Tests on Rubber Undercarriage Shock Absorbers. (Z.F.M., Vol. XX1, No. 6, 28/3/30, pp. I33-137.) (5.51/13 132 Germany.)

Shock tests were set up in which the maximum load was applied in a very short time. In comparison with ordinary slow loading tests ine maximum stresses were from to to 20 per cent. greater.

The stress-strain diagrams were complicated by surface friction.

A number of hysteresis loops are reproduced and a comparatively simple formula is given which relates the time of impulsive loading to the maximun stress.

Wires, Cords and Ropes in Aircraft Construction. (M. Abraham, L.F.F., Vol. VII, No. 2, 6/5/3o, pp. 73-1 36.) (5.54/r 3 r 33 Germany.)

General rigging diagrams are used to indicate every position in an aeroplane in which tension members may be used and in which control wires may be fitted.

Photographs illustrate nearly every kind of wire, cable, turnbuckle, eyelet, etc., in common use, and testing apparatus of various types.

The results of tests are given in tables and graphs and cover a wide range of English, American and particularly German practice.

The effects of corrosion are serious and in some cases the uncertainty arising from the use of tension members is to be avoided by employing other elements of construction.

The present paper contributes to rational design with a reliable load factor.

Brakes and Tail Skids for Large Aeroplanes. (Luftfahrt, Vol. XXXIV, No. 3, March, 1930, p. 76.) (5.55/1 $33^{1} 34$ Germany.)

The damage done by tail skids to aerodrome surfaces has led to investigation by the D.V.L. and to their production of a new type of skid in conjunction with a compressed air brake on the wheels of the main carriage. Specification of the compressed air brake apparatus is given, accompanied by a diagrammatic sketch and three photographs. One photograph shows that the tail skid is maturally of a low resistance type, while another shows the skid replaced by a pivoting wheel. Details of weights are given.

Wheel Brakes. (Luftwacht, No. 4, April, I930, pp. I76-182.) (5.55/13135 Germany.)

Details are given with photographs and diagrams of the Lockhead, Ford. and Sikorsky hydraulic brakes, and the Palmer and Knorr compressed air brakes.

Buckling Tests on Thin Struts with Fairing. (H. Hertel, L.F.F., Vol. VIII, No. I, pp. I-1 $\left.7,24 / 5 / 3^{\circ}\right) \cdot(5 \cdot 56 / 13$ I 36 Germany. $)$

The distribution of stresses between strut and fairing is investigated mathematically and a simple expression is found for the combined strength.

Various types of fairing are shown in sketches, and tests on fairing alone and on the complete strut were carried out both for bending and buckling. Six tubular steel struts without fairing were tested for both bending and buckling. Component parts of the fairings were tested separately.

The arrangement of the apparatus for the buckling tests is shown in diagrams and in a photograph. The effects of friction in the end pins is discussed mathematically and in favourable cases may render the pin joint equivalent to a fixed joint. Numerous determinations of deflections and of buckling loads are embodied in tables and in fifty charts, in some cases for five different strut lengths.

Riveting the fairing to the strut at one point only may reduce the strength by local failure. Packing picces at one-third and two-thirds of the length and 
at the ends were sufficient to distribute the buckling load between strut and: fairing.

For sheet metal above $0.5 \mathrm{~mm}$. thick in the fairing, the agreement between calculation and test values was good:

Biscontinuities in the bength of the fairing diminished its stiffening effect to. a small fraction of the original value.

Buckling and Bending Strength of Struts with Hollow Sections. (O. Steinitz, Z.F.M., Vol. XXI, No. 3, I4/2/30, pp. 57 to 60 .) (5.56/13137 Germany.)

The simple formula for a section bounded by concentric circles is modified by the introduction of empirical coefficients. It - is stated that the modified formula gives rapid approximate estimation of the modulus of certain types of hollow sections with sufficient accuracy for practical purposes.

Test Methods for Resistance of Solid Rubber Tyres to Shock. (E. Marquard, Tech. Mech. Therm., Vol. 1, No. 6, June, 1930, pp. 209-218.) (5.57/ $3^{\mathrm{i}} 3^{8}$ Germany.)

Three grades of hardness are arbitrarily qualified as soft, hard and very hard, and are represented diagrammatically by comparative stress strain diagrams, the maximum strain energy being approximately equal.

The pendulum test apparatus and the mounting of the specimens are fully described and elementary formula of reduction are worked out.

The test results under different pendulum impacts are plotted.

\section{Gliding}

Motortess Flight. (Aviation, Vol. XXVIII, No. 19, 10/5/30.) (5.8/13139 U.S.A.)

P. 949. At San Diego, Calif., J. Barstow, on a Bowlus glider, achieved an unofficial record by soaring for $\mathrm{I}_{5} \mathrm{hr}$. $\mathrm{I}_{3} \mathrm{~min}$., attaining an altitude of I,,$\infty$ feet.

P. 951. At a glider meeting near New York, the longest flight was one of 44 seconds by W. H. Bowlus, compared with his own record of nine hours. A few details are given of the entries and methods of starting.

Gliding Expedition of the Rhön-Rossittengesellschaft Society to the Rax-Alpe, Austria, Jan.-Feb., 1929. (Report by R. Kronfeld and Dr. W. Kühnert, Z.F.M., Vol. XXI, No. 4, 28/2/39, pp. Io0-108.) (5.8/13140 Germany.)

Photographs of the mountainous district and a contour map with contours at every 100 metres from $500 \mathrm{~m}$. to $2,000 \mathrm{~m}$. indicate the nature of the country.

The routes followed are show in plan on the contour map and as far as possible in perspective on the photograph. Sketches are added showing the approximate flow in the neighbourhood of the mountain side. The configuration of the flow set up by secondary eddies could not be anticipated. A barogram: records a tlight reaching $3,200 \mathrm{~m}$.

Remarks on Dynamical Gliding. (L. Prandt1, Z.F.M., Vol. XXI, No. 5, 14/3/30, p. 116.$) \quad\left(5.8 /{ }^{1} 3^{1} 4^{1}\right.$ Germany. $)$

A brief discussion is given of the possibility of the employment of a pulsating wind as a source of sufficient energy for gliding. 
Technical Report of the Tenth Gliding Competition at the Wasserkuppe in Rhon, 1929. (A. Lippisch, Z.F.M., Vol. XXI, No. 4, 28/2/30, pp. 92-98.) (5.8/13142 Germany.)

A table gives the principal dimensions and weights of eighteen types of glider taking part in the competition.

Photographs and dimensioned sketches of seven gliders are given.

Formulæ of reduction are given to compare the performance.

Regulations for Gtiders. (Aviation, Vol. XXVIII, No. 25, 21/6/30, p. 1226.) (5.8/13.143 U.S.A.)

A brief surnmary is given of regulations issued by the Department of Commerce to bring gliders within the scope of airworthiness certificates. No new regulations are laid down.

\section{A coustics}

Analysis of Measurement of Noise Emitted by Machinery. (B. A. G. Churcher and A. J. King, Jrnl. I.E.E., Vol. LXVIII, No. 397, Jan., 1930, p. 97.) (6.26/i $3^{1} 44$ Great Britain.)

Discussion of the above mentioned paper (sec abstract No. I3/12343) is printed in Jrnl. I.E.E., 68/402, June, 1930, p. 780 .

Oscillations of Diaphragms in Pulsating Fluids, with a Contribution to the Theory of Hearing. (W. Kucharski, Phys. Zeit., Vol. XXXI, No. 6, I5/3/30, p. 264.) (6.26/13r45 Germany.)

A simplified model of the cochlea is investigated mathematically and it: appears that the primary result of an incident sound wave is to cause the liquid in the labyrinth to oscillate. This oscillation produces a vibration of the basilar membrane by inertia and friction. By means of special fibres in contact with this membrane the distribution of the amplitude is measured and transmitted to the brain.

Reverberation in "Dead" Rooms. (C. F. Eyring, Bell. Tele. Lab., B.465, Apl., I930.) (6.26/13146 U.S.A.)

When a uniform source of sound operates for a time in a closed room and is then cut off, repeated echoes maintain reverberation, which dies down in steps.

At each reflection the energy is reduced in a proportion depending on the coefficient of absorption. The reverberation ceases to produce an audible sound after an interval called the reverberation time.

In Sabine's formula the reverberation time is proportional to the volume of the room divided by the coefficient of absorption; with a factor depending only on the shape of the room. A more general expression is devised here, whereby each element of surface and its absorbing power is considered separately.

It is applied to sphere, circular cylinder and cube, and particular forms of the expressions are found for these cases.

For more complicated cases, the appropriate expression may be built up by suitable averaging and summing. Graphical examples are given of the time rate of reduction of intensity calculated for different coefficients of absorption, and comparison is made with the simple formula.

The arrangement of conbections in the valve amplifier microphonic apparatus used, is exhibited in a diagram, and a typical set of readings is given graphically.

As an example of numerical applications, reverberation times and coefficients of absorption are calculated by Sabine's formula and by the new formula and show a reduction in reverberation time of roughly 50 per cent. over the usual 
concert range. This is of considerable importance in predetermining the extent and cost of absorbing material required to obtain a specified reverberation time.

Law of Stifing of Sound by Curtains and Cushions. (J. Larmor, Proc. Cam. Phi1. Soc., Vol. XXVI, Pt. 2, April, 1930, p. 231.) (6.265/13147 Great Britain.)

Critical comment is made on the result obtained by the U.S. Bureau of Standards that the relative absorption of the energy of sound waves by a curtain is independent of the incidence, following Green, Rayleigh and Kelvin. An expression is formed for the frictional loss of energy due to the uncompensated tangential step at the inter-face between two fiuids, and is found to be negligible. Consideration is extended to a train of sound waves incident obliquely on a porous surface, and the stifling of sound is found to increase with the obliquity, being doubled at $60^{\circ}$ incidence.

Navigational Instruments, Etc.

The Gyrorector. (L'Aerophile, Vol. XXXVIII, Nos. I/2, Jan., I930, p. I6.) (6.32/r 3 I 48 Fiance.)

A brief description with a photograph and diagrams of dial readings is given. The indication is given by the difference between a pendulum indicating the apparent vertical and the gyroscope giving the artificial horizon.

It is stated that the apparatus was used with success in the flight from Paris to Manchuria.

Elastic After-Dffects, Elastic Hysteresis and Temperature Compensation in Aneroid Capsules. (L. Scriba, L.F.F., Vol. V, No. 3, p. 107-136.) (6.33/ 3 I 49 Germany.)

The object of the investigations is purely practical, but various theories of hysteresis are discussed, and Prandtl's model for illustrating the molecular basis of hysteresis is reproduced with the object of throwing light on the observed facts.

Three types of test apparatus were constructed:-

I. An apparatus for the mechanical tests of capsules.

2. An optical apparatus for the same purpose, and

3. An optical apparatus for testing flat plates.

The elastic after-effects were found to depend upon the time of loading and to agree with the theory of Bennewitz for small loads; but for higher loads the observed value was less than the calculated value.

The width of the hysteresis loop increases more rapidly than in proportion to the temperature. A new type of temperature compensation was devised depending on the differential expansion of the cylinder and the end plates of the capsule. Finally, a new instrument has been designed with satisfactory elastic and thermal properties in which the cylindrical body is very stiff and the elastic forces are supplied by a special form of the end plates.

Eighteen references are given.

A Method of Measuring Turbulence in the. Atmosphere. (E. Huguenard, A. Magnan and A. Planiol, C.R., Vol. CXC, No. 24, I6/6/3o, pp. I437-1439.) (6.382/1 $3^{1} 5^{\circ}$ France).

The instantaneous velocity of the wind and the angle made with the mean direction are recorded by a hot wire anemometer and analysis of the curves determines the turbulence, defined as the apparent motion of the air to an observer travelling with mean velocity. Observed periodic motions are accounted for by the existence of large vortices. 


\section{Engine Instruments, Etc.}

Investigation of Flow in Floating Disc Flow Meters. (G. Ruppel and K. J. Umpfenbach, Tech. Mech. Therm., Vol. I, No. 6, June, 1930, pp. 225-233.) (6.5I/I $3^{1} 5^{\text {I }}$ Germany.)

ParT I.-The disc is mounted axially in a truncated cone, and is carried upwards by the flow to a position of equilibrium. The various positions are calibrated against the flow. speeds.

Five photographs show two-dimensional formation of eddies at different flow:

PART II.-The measurement of viscosity of oils and of water is discussed.

Rapidly Fluctuating Pressures Measured Electrically by Indicator Combined with Sparking Plug. (E. J. Martin and D. F. Caris, Autom. Ind., Vol. LXII, No. 7, 15/2/30, p. 230.) (6.57/1 $3^{1} 5^{2}$ U.S.A.)

The requirements of an internal combustion engine indicator are ability to withstand high engine temperatures, small mass in the indicating mechanism, simple linkages, and dead-beat reading. Sectional drawings, photographs and description are given of an indicator designed to meet these requirements. Photographic records are given of the calibration curve, and of imposed simple harmonic pressures up to 30 cycles per second, I, 800 r.p.m. Further photographs show actual records, which bring out detonation, pressure oscillations, the effect of a connecting tube, and other phenomena. Records were also taken of low pressure variations such as occurred in the intake manifold.

It appears that considerable difficulties of recording at high frequency still remain to be overcome, particularly the provision of a suitable oscillograph.

New Types of Sensitive Silica Manometers. (B. Lockspeiser, J. Sc. Insts., Vol. VII, No. 5, May, I930, pp. I45-I5I.) (6.57/I3I53 Great Britain.)

The materials used are silica rod, tube, and plate. A Bourdon type of elastic control is obtained by blowing a spherical bulb at the end of a tube, collapsing it along an axis, piercing the surface of internal contact and cutting and sealing the annulus thus formed. A diaphragm type of elastic control is obtained by blowing a spherical bulb at the end of a tube and collapsing the hemisphere remote from the tube to a more or less plane diaphragm.

Details of working up the necessary indicating attachments are given. The Bourdon type gives a nearly linear scale. 'The range is limited by the strength of the cut annulus to about 30 or $40 \mathrm{~cm}$. of water. The diaphragm type gives. a logarithmic scale with a probable error up to $3^{\circ} \mathrm{mm}$. of water of about $\mathrm{I} / \mathrm{I} 400$, and withstands pressures up to an atmosphere.

The whole elastic structure being of fused silica there is no hysteresis error.

Electric Pressure Gauges. (H. Gerdien, Z.F.M., Vol. XXII, No. 2, Feb., 1930, p. 68.). (6.57/1 $3^{1} 54$ Germany.)

The gauge depends on the variation of electrical capacity in a high frequency circuit. Types of gauges for measuring high pressure or tension such as occur in presses and rolling mills are described as well as a model for measuring the torque transmitted through a shaft. The gauges undergo small inertia force on account of the small displacements required. Pressure-variations during $1 / 1000$. sec. are easily recorded. A bibliography is given. 
Indication of Rapidly Changing Pressures by Means of Resonance Curves. (K. Schnauffer, L.F.F., Vol. VI, Part 4, 14/2/30, pp. 126-I 36, I02nd Report of the D.V.L.) (6.59/1 $3^{\mathrm{I}} 55$ Germany.)

A description is given of an electrical pressure indicator apparatus in conjunction with an amplifying set. Diagrams of two alternative arrangements are given.

The actual pressures are measured by a Geber condenser with a moveable elastic plate connected to a pressure diaphragm. The capacity of the condenser is accordingly altered by the pressure. A discussion is given on the adjustment of the apparatus and the sources of error. A large number of diagrams is reproduced and interpretations are given of their peculiarities.

The question of calibration raises the fundamental difficulty of all such methods. An example of calibration curves is given graphically, and some of the errors arising are discussed numerically. Further developments of the apparatus are described and a modified instrument gives direct proportionality between pressure and displacement. Twenty-four indicator oscillograms are reproduced, with interpretations of their peculiarities. It does not appear that any final solution of the principal difficulties has been reached, but there is no doubt that these instruments are capable of giving much valuable information on the pressure changes in the cylinder.

A list of thirteen references is given.

\section{Optics}

Penetration of Light through Fog. (S. H. Anderson, Aviation, Vol. XXVIII, No. $19,10 / 5 / 30$, p. 93 I. $)\left(6.61 / 13^{1} 5^{6}\right.$ U.S.A.)

The article is of interest in that the tests were carried out in artificial fogs at the Wright Field Laboratory. The method of producing artificial fogs is discussed and a table gives the coefficient of absorption at different parts of the spectrum. Graphical charts are given, showing the percentage transmission in comparison with deep red light both of shorter wave colours and of infra-red rays.

The results are considered incomplete, and an appreciation of the method should await further experiment.

Scattering of Light. (G. F'. A. Stutz, J. Franklin Inst., Vol. CCX, No. I, July, I930, pp. 67-86.) (6.61/1 $3^{1} 57$ U.S.A.)

An experimental verification is made of Rayleigh's theory of scattering, using zinc-oxide in suspension in water. The diameters of the particles varied from 0.135 to 1.23 microns. The distribution of the scattered light for different wave lengths and the depolarisation were measured and tabulated. Sketches and photographs of the apparatus are given.

Improvement of Nocturnal Vision by Telescopes. (F. Lohle, Zeit. Instrum., 49, Dec., 1929, p. 595.) (5.7 I// 3 I 58 Germany.)

Improvement in vision does not increase with magnification but depends on the loss of light by absorption on reflection, as well as on the amount of light entering the pupil. A Galilean telescope gives better results than prismatic glasses. 


\section{Miscellaneous Instruments, Etc.}

Portable Vibrograph. (Instrument World, Aug., I930, p. 9I.) (6.72/13159 Great Britain.)

This instrument is designed for making spot tests of high period vibrations and can be applied to a vibrating surface in any position, horizontal or vertical. The vibrations are conveyed by a toe on the instrument and transmitted through a series of levers to a fine stylus moving over a celluloid film. An independent time record is traced on the film by a second stylus.

The Free and Forced Symmetrical Oscillations of Thin Bars, Circular Diaphragms and Annuli. (A. G. Warren, Phil. Mag., Vol. IX, No. 6o, May, r930, p. 881.) (6.73/13160 Great Britain.)

A number of applications of elastic theory are worked out within the scope of the article. The form of the solutions and the numerical relations given graphically have applications in design involving vibrating reeds and discs.

\section{Stability and Control}

The Art of Flying Landplanes and Seaplanes. (N. Macmillan, Jrnl. R. Aer. Soc., Vol. XXXIV, No. 232, p. 305.) (7.0/行16I Great Britain.)

This paper gives the pilot's point of view in applying the qualities of an aeroplane as determined by systematic test flights to carry out specific military or commercial purposes. The polar diagram showing gliding angles and speeds from an inverted stalled flight through inverted flight and nose-dive to normal flight and stalling speed is instructive.

Spin in Aeroplanes. (R. Institution Lecture, H. E. Wimperis, Engineering, Vol. CXXIX, No. 3358, 23/5/30, p. 674.) (7.14/13162 Great Britain.)

A survey is given of the causes and available remedies. The uncertainty of full-scale experiments and the incomplete representation of effects by model experiments leaves a number of essential factors indeterminate, so that relative facts cannot be disentangled. With modern high speed aeroplanes such high speeds of spin might be obtained that the gyroscopic couples might overcome aerodynamic controls exercised by the pilot. Kinematic records taken from the ground and properly interpreted might give more precision to full-scale experiments.

Mathematical Investigation of Spin. (Fr. Haus, Rev. Gen. de 1'Aer., No. I3, Dec., ig29, pp. I03-I70.) (7. I4/1 $3{ }^{16} 6_{3}$ France:)

The author summarises the dynamical principles involved and forms the equations and their solutions subject to the usual simplifications. The work follows the lines of recent reports and memoranda.

Flight Test Determination of Longitudinal Stability. (H. Blenk, L.F.F., Vol. VI, No. 5, 22/3/30, PP. I5I-I55, 174th Report of D.V.L.) (7:21/13564 Germany.)

A weight sliding fore and aft and a water tank in the tail enabled the position of the c.g. to be varied in a known manner. The elevator position and the dynamic pressure were recorded, and calibration curves and specimen records are reproduced.

The rudder displacements required for steady flight at given throttle are plotted against horizontal flight speed, for different positions of the c.g. The observed points lie smoothly on curves. The coefficient of normal forces on the tail surface is plotted against speed and the points are considerably scattered, but 
the mean values are satisfactory. The curve of the static moment of stability shows that it diminishes as the c.g. moves aft, and as the throttle opens, the latter on account of the increase in the airscrew blast.

Comparison with Göttingen model results was considered satisfactory.

Stability of Aeroplanes. (R. Pris, Rev. Gen. de l'Aer., No. I1, Nov., 1929, pp. 25-80.) (7.21/1 $33^{16}{ }_{5}$ France.)

The mathematical theory of stability is summarised. German, English and French results are tabulated and plotted graphically and discussed.

\section{Engine Design}

Standardisation and Nomenclature of Fuels and Engines. (A. A. Herzfeld, Autom. Tech. Zeit., Vol. XXXIII, No. I7, 20/6/30, p. 428.) (8.0/13166 Germany.)

At the present world power congress standardisation of engine and fuel is recommended. The classification of engines by constant volume and constant pressure combustion is opposed and classification by type of ignition is advocated, with the nomenclature "igniter engines" and "burner engines" according as the fuel is ignited by extraneous agency (the igniter) or burns at the injection valve, like a torch.

Development of Aircraft Engines. (W. Kamm, L.F.F., Vol. VI, No. 4, 14/2/30, pp. 87-9I, I 56 th Report of D.V.L., read at D.V.L.) (8.0/13167 Germany.)

Tables are given showing the change of the principal parameters from year to year for common types of engine, both German and of other nationalities.

The following are exhibited diagrammatically :-

Change per year of weight per h.p., mean effective pressure, mean piston speed, mean bearing pressure at maximum explosion pressure, mean bearing pressure at mean effective pressure, peripheral speed of the crank pins in the connecting rod bearings, peripheral speed of the cranks in the main bearing, load on crank pins corresponding to maximum explosion pressure, load on the crank pins corresponding to mean effective pressure.

A number of generalities on development are added.

It is considered that an 800 h.p. high performance engine (suitable for war purposes) can be adapted as a commercial aircraft engine at a cruising rating. of 400 h.p.

Thermodynamical Problems in Aeronautical Research. (K. Löhner, L.F.F., Vol. VI, No. 4, I 4/2/30, pp. III-I 20, I6oth Report of the D.V.L.) (8.1/1 3 I68 Germany.)

A brief general survey is given of the heat cycle. Reference is made to use of cooling media other than water or air. Considerable space is given to the physical properties of fuels' in charts and in a table in which 86 physical coefficients are tabulated for the paraffins from hexane to duodekane, and for benzol, toluol and napthaline.

Two types of indicating apparatus are described and examples of indicator diagrams are given.

Forty-three references are given.

Test Apparatus for Research on Aircraft Engines. (W. Janson, L.F.F., Vol. VI, Pt. 4, I4/2/30, pp. 121-125, I6Ist Report of the D.V.L.) (8.18/13169 Germany.)

A description is given with photographs and diagrams of engine bench test 
apparatus at the D.V.L. laboratory, including a rotating bench for measuring gyroscopic moments.

Water-Cooled Aero Engines. (A. J. Rowledge, J. Roy. Aer. Soc., Vol. XXXIV, No. 235, July, I930, pp. 578-602.) (8.2/1 3170 Great Britain.)

The author gives a general survey of the problem of engine design, quotes some of the figures achieved so far, and anticipates the lines of future development and improvement. The discussion follows similar lines. In particular critical comments by Mr. Pye are a useful complement. The paper and discussion include crankshaft speeds, explosion pressure, temperatures, supercharging, gearing variable pitch airscrews, cooling systems, exhaust driven turbines, fuels, frontal area, torsional damper, etc.

Calculations of Torsional Oscillations in Diesel Engines. (E. Göller, Z.V.D.I., Vol. LXXIV, No. I6, 19/4/30, p. 497.) (8.22/1317i Germany.)

The inertia of the moving parts of the engine, of the flywheel, and of the driven machinery is the principal factor. The combined frequency is calculated from the partial frequencies by a standard formula given in approximate form. Two examples are worked out numerically for a six-cylinder engine.

The errors in the formulæ are plotted for different conditions, and in the worst case are 4 per cent. in defect.

Torsional Oscillations in Engines with Cylinders in Line. (A. Stieglitz, L.F.F., Vol. IV, No. 5, 24/7/29, pp. I33-I 58.) (8.22/13172 Germany.)

Torsional resonance is regarded as the principal cause of engine failure. The theory is discussed in a general manner and test results covering the design details of certain standard types of aero engines are used to give practical scope to theoretical results. Much light is thereby thrown on troubles arising from torsional resonance. The use of vector diagrams is introduced on analogy with the theory of electro-dynamical machines. These diagrams exhibit clearly the effect of damping in throwing the forces out of phase in such a way as to reduce their maximum numerical value.

Indicator diagrams are used to determine the pressure forces. The inertia forces are calculated in the usual manner. The inevitable simplifications are introduced into the differential equations which are formed and solved. The natural frequency of the crankshaft is determined by experiment and compared with the value calculated. Examples of critical speeds are worked out for a sixcylinder and a 12 -cylinder engine. Resonance amplitudes measured from torsion diagrams are used to determine approximately the damping required. The theory of linear damping is worked out and formulæ are developed. An attempt is made to extend the results to solid friction damping. A method is developed for rapid practical calculations in the case of similar types of engine, but for new types various modifications will be required.

Recent Results on Torsional Oscillation. (A. Stieglitz, L.F.F., Vol. VI, Part 4, 14/2/30, pp. IO3-110, I59th Report of the D.V.L., read at D.V.L.) (8.22/13 173 Germany.)

Failures of shafts are due to the super-position of torsional oscillation loads on the steady load.

The elastic energy relations were considered and the exciting and damping forces discussed; the specific work is plotted graphically and indicates the critical points.

The influence of the order of firing requires attention, and the most favourable arrangement for a six-cylinder engine is laid down. 
The effectiveness of a damping arrangement was examined and the most favourable adjustment determined.

Resonance curves are prepared from engines with and without dampers. A brief account of methods of measurement is added. A discussion follows.

Oscillations in Aircraft Power Plants. (K. Lürenbaum, L.F.F., Vol. VI, No. 4,

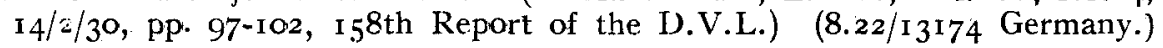

A brief summary is given of the possible vibrations in the power plant, with particular reference to resonance. Torsional vibrations receive special consideration as being the more important and dangerous. A description is given of test apparatus and in particular of special elastic couplings with rubber packing, designed for the purpose of damping any serious resonance at the critical speeds which are considered unavoidable.

Bending Oscillations of Engines. (J. Geiger, Z.V.D.I., Vol. LXXIV, No. I7, 26/4/3o, pp. 542-544.) (8.22/13175 Germany.)

The side pressure of the piston on the cylinder wall subjects the engine and its foundation to periodic forces in the plane at right angles to the crankshaft, which is specially important in large Diesel engines. The resulting vibrations were recorded by the author's vibrograph, and by suitable arrangement of the order of firing and the position of the crank throws, the transverse vibration was reduced.

Torsional Vibration in Multi-Crankshafts. (A. Stodola, Z.A.M.M., Vol. IX, No. 5, Oct., I929, p.p. 349-360.) (8.22/1 3 I 76 Germany.)

The vectorial method is applied to a six-cylinder Diesel engine. By suitable choice of masses concentrated on the shaft as well as by adjustment of the elastic forces, it is possible to avoid dangerous oscillation, although the frequency of the applied force agrees with one of the free frequencies of the shaft, a case of " apparent resonance" not generally considered in text books. Although this solution of the torsional oscillation problem is not generally practicable with existing engines, the question is one of considerable theoretical interest.

\section{Angular Distortion of Crankshafts. (C. A. Norman and K. W. Stinson, Ohio State University Bulletin, No. 43, 1928, 20 pp.) (8.22/13177 U.S.A.)}

The authors quote Carter's formula, which they consider a good approximation, but offer a formula of their own which they consider more accurate in some respects. The numerical values given by their formula and by Carter's are tabulated against experimental results for eleven crankshafts. The mean calculated figure is about io per cent. greater than the experimental figure. Extreme cases are $-I I$ and +28 per cent.

\section{Crankshaft Fractures. (Flug, No. 5, May, 1930, p. 6.) (8.22/1 3178 Austria.)}

From experiments at Adlershof with crankshafts changes of section and the presence of oil holes reduce the fatigue strength of the finished shaft to approximately 60 per cent. of a uniform bar. As the fatigue strength is about half the ultimate tensile strength, static tests are of indirect importance. The fatigue limits should be determined under conditions approaching working conditions. The material affects the ultimate fatigue limit in an uncertain way; any high grade steel behaves satisfactorily if the design of the shaft is correct, but an increase in the surface hardening of the material raises the fatigue limits sensibly. 
The Waldstein Coupling. (Z.V.D.I., Vol. LXXIV, No. I5, I2/4/30, p. 482.) (8.2205/13179 Germany.)

An arrangement of endless belts, coupling pairs of roller pins, one mounted on the driving side and one on the driven side, and kept taut by an inner system of stirrups and belt, distributes the stresses evenly over the system for the permissible range of torque, and also takes up a certain amount of eccentricity between driving side and driven side.

Recent Experiments on the Wear of Metals. (W. Fink, Z.V.D.I., Vol. LXXIV, No. $3,18 / 1 / 30$, pp. $85-87$.$) (8.23/13180 Germany.)$

The wear of metals is largely due to oxidation brought about by intimate contact with oxygen under pressure, which continues even if the load is insufficient to cause mechanical breakdown. If air is replaced by an inert gas there is no oxidation; the friction between metal surfaces is considerably reduced and the wear is reduced to that due to the tearing off of material, which can be prevented altogether by suitable adjustment of the load.

Bearing Bronzes with the Additions of Zinc and other Metals. (R. L. Dowdell and C. E. Eggerschwiller, S.A.E., Vol. XXVII, No. I, July, 1930, pp. 45-55.) (8.23/1 3 I 8 I U.S.A.)

Specifications are given of seven basic copper-tin-lead bearing bronzes, which were subjected to tests for Brinnell hardness, resistance to impact, pounding and wear.

The influence of additions of zinc, phosphorus, nickel and antimony, were investigated. In all forty alloys of which the chemical analysis is given were tested. Further specifications are given of fifty-four different bearing bronzes in common use.

Questions of lubrication are also considered.

Photographs and dimensioned sketches of test specimens with perspective drawings of three-dimensional models with ruled surfaces, indicate the results of tests. A number of micro-photographs are given.

Thick-Walled Cylinders under Pressure. (R. W. Bailey, Engineering, Vol. CXXIX, No. $33^{6} 3$, pp. 818-819.) (8.24/13182 Great Britain.)

The creep of the material under stresses beyond the elastic limit at a constant temperature is discussed. The discussion is extended to the cases of variable temperature distributions set up by radial transmission of heat inwards and outwards. The creep of the cylinders under internal pressure is shown to be connected with the creep of the material in shear provided the material is approximately isotropic.

\section{Engine Cooling}

The Condensation of Steam in Films and Drops. (Tech. Mech. und Therm., Vol. I, No. 2, I930, p. 53.) (8.3/1 $33^{1} 8_{3}$ Germany.)

In experiments, steam impinging on a flat plate condensed in fine drops with a heat transfer of $40,000 \mathrm{Kal} / \mathrm{m}^{2} h^{\circ} \mathrm{C}$. If the plate was etched the steam condensed in a film with a heat transfer of only $.5,000 \mathrm{Kal} / \mathrm{m}^{2} h^{\circ} \mathrm{C}$. At the centre of the cooling water jet the transfer was $70,000 \mathrm{Kal} / m^{2} h^{\circ} \mathrm{C}$. for a jet velocity of 3o ft. per sec. 
Coefficient of Heat Transfer from Internal Tube Walls. (A. Eagle and R. M. Ferguson, Proc. Roy. Soc., A. Vol. CXXVII, No. 806, pp. 540 to 566 .) (8.3/1 $3^{184}$ Great Britain.)

Osborne Reynolds' formula for heat transfer is modified to take into account a boundary layer of laminar flow.

Using dimensional methods for reduction of observations under different conditions, three experimental coefficients are determined and tabulated, along with three derived coefficients.

The empirical treatment is referred to as a "theory."

The soluble problem of laminar flow, referred to here as viscous flow, is briefly discussed. A diagram and description of the experimental apparatus are given.

Theory of Heat Conduction. (M. S. van Dusen, Bur. St. Jrnl. Res., Vol. IV, No. 6, June, 1930, p. 753.) (8.3/13185, U.S.A.)

The problem of heat flow where the thermometric conductivity is a function of the temperature is considered.

A new variable is introduced and the transformed equation takes the form:-

$$
\nabla^{2} U=0
$$

with a special form of the boundary condition.

An example is worked out in cylindrical co-ordinates.

The result may have an application in slow viscous fluid motion with variable viscosity.

\section{Lubrication}

Lubricants, German Association for Technical Material Testing. (Erdol and Teer, 6, 46-8 (I930), Chem. Abstr., Vol. XXIV, No. II, 10/6/3, p. 2872.) (8.4I/1 3 I 86 U.S.A.)

The ageing of oils is entirely due to oxidation. Samples kept in a vacuum do not deteriorate. Known oxidation inhibitors were without effect. A suitable negative catalyst is being sought.

Some Notes on Oil Purification as Applied to Air Engines. (G. Manley, Flight, Vol. XXI, No. 39 (Aircraft Engineering Section), page 69, I929.) (8.44/1 3187 Great Britain.)

An effective filter will remove most of the impurities found in lubricating oils in an engine. Other methods are discussed.

\section{Fuels}

New Method of Determining the Corrosive Action of Engine Fuels on a Series of Common Metals. (Wawrziniok, Autom. Tech. Zeit., Vol. XXXIII, No. I, 10/1/30, p. 28, Vol. XXXIII, No. 2, 20/1/30, p. 58, Vol. XXXIII, No. 4, Io $/ 2 / 30$, p. I I0. $)\left(8.5_{1}^{1 / 1} 3188\right.$ Germany.)

The immersed samples were subjected to an oscillatory motion in the presence of air and fuel. Fuels containing alcohol were generally found to show more corrosion than ordinary petrols. In every case it was found that some of the metal had gone into solution in the fuel.

Survey of Fuel Analysis. (G. Bandte, Autom. Tech. Zeit., Vol. XXXIII, No. 17, 20/6/30, pp. 430-432.) (8.51/1 3189 Germany.)

Tests in the laboratory have failed to decide the suitability of a given fuel for internal combustion engines. Midgley's bouncing pin apparatus is the most convenient for direct engine tests. In its new form instead of measuring the 
amount of electrolytic gas evolved by timing with a stop watch, the heat generated in the bouncing pin circuit is measured by a thermo-junction and recorded directly on a voltmeter.

Fuels and Dopes for Aircraft Engines. (A. E. Dunstan and F. B. Thole, Jrnl. R. Aer. Soc., Vol. XXXIV, No. 232, p. 329.) (8.51/1319o Great Britain.)

The physical chemical and thermal properties are defined and classified. The more elusive anti-knock value of fuels is discussed. In the discussion and reply the possibilities of replacing natural light fuel by cracked tuels was reviewed. The reduction of fire risks by using fuel of higher flash point was considered.

Some Phenomena of Gum Determinations in Motor Fuel. (E. C. Herthel and F. A. Apgar, Am. Petroleum Inst. Proc., No. I, Sec. III, I24-32 (I930), Chem. Abstr., Vol. XXIV, No. 8, 20/4/30, p. 1967.) (8.51/1319r U.S.A.)

Gum determinations by the copper dish method, the steam oven method, and the oxygen absorption method cannot be correlated with one another, nor do they agree with storage performance tests which are affected by light and moisture. The effect of certain metal catalysts is given.

Standard Method for Determining Gum Content of Cracked Gasolines. (I. E. Bespolov, Azerbaidzhanskoe Neftyanoe Khozyaistvo, 1930, No. I, 57-8, Chem. Abstr., Vol. XXIV, No. 8, 20/4/30, p. 1967.) (8.512/13192 Russia.)

Chemical inhibitors have been found which prevent loss of knock-rating during accelerated oxidation. Processes for the restoration of cracked petrol which has depreciated in knock-rating have been developed.

The Metal Carbonyls. (R. L. Mond. J. Soc. Chem. Ind., Vol. XLIX, No. 24, I $3 / 6 / 30$, p. 27 I T ; No. $25,20 / 6 / 30$, p. 283 T; No. 26, 27/6/30, p. 287 T.) (8.514/13193 Great Britain.)

The manufacture of nickel, iron, cobalt, molybdenum, ruthenium, chromium and tungsten carbonyls is discussed.

As an anti-knock, iron carbonyl is the most interesting and the continental fuel known as Motalin contains 0.2 per cent. in solution with ordinary petrol. The carbonyls as a possible source of a pure metal have not so far received commercial application, with the exception of the formation of the metallic mirror on the interior of thermos flasks by the decomposition of nickel carbonyl.

An extensive bibliography including a list of patents is added.

Anti-Knock Testing and Performance. (E. Bartholomew, Oil and Gas, J. 22 , No. 22, 32-3, 145 (1920); cf. C.A. 24, 2280, Chem. Abstr., Vol. XXIV, No. II, Jo/6/30, p. 2870.$)\left(8.5^{\text {I } 4 / 13194 ~ U . S . A .) ~}\right.$

Generally speaking, increase of speed or temperature lowers the detonation of fuels containing ethyl fluid, but raises it in the case of benzol mixtures.

Stabilisation of Knock Kating, Gums and Colour of Gasoline by Chemical Inhibitors. (G. Egloff, W F. Faragher and J. C. Morrell, Am. Petroleum Inst, Proc,, No. I, Sec. III, i i $2-7$ (1930), Chem. Abstr., Vol. XXIV, No. $8,20 / 4 / 30$, p. 2967.$) \quad(8.514 / 13$ I95 U.S.A.)

There is no definite connection between the formation of gum and the lowering of anti-knock value. Experiments were carried out with chemical inhibitors which retard gum formation during storage. Processes for the restoration of cracked petrols which have fallen off in anti-knock value during storage are described. 


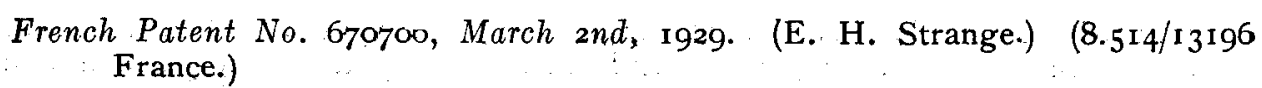

Certain compounds of iodine, including iodoaniline, are proposed as antidetonators in proportions of the order of $1 / 500$.

Flame Characteristics of "Pinking" and "Non-Pinking" Fuels, Part II. (G. B. Maxwell and R. V. Wheeler, Fuel, Vol. IX, No. 3, March, 1930, p. I21.) (8.514/13197 Great Britain.)

Simultaneous photographs of the flame travel and pressure rise were taken sn a closed cylinder 15 in. long and 6 in. diameter. Benzine, pentane and mixtures, gaseous fuels like hydrogen, and the addition of amyl nitrite, carbon bisulphide, etc., were investigated. Previous conclusions were verified. Pinking is due to the formation of stationary waves, which àre maintained by residual chemical energy; after the main flame has traversed the mixture: Turbulence destroys pinking by delaying the formation of the stationary wave. Dopes act by making the combustion continuous in the wake of the flame. Auto-ignition in front of the flame does not produce detonation.

Effect of Tetrapthyl Lead, Hot Surfaces and Spark Ignition on Flame and Pressure Propagation. (M. Souders, Jr., and G. G. Brown, Ind. and Eng. Chem., No. 21, 1/12/29, p. 126r.) (8.514/13198 U.S.A.)

Tetraethyl lead vapour does not retard combustion until it is decomposed by the flame. Auto-ignition by a hot plate is prevented or delayed by the presence of decomposed tetraethyl lead.

\section{Carburettors and. Feed Systems}

Altitude Control of Aeroplane Engines. (J. Pettit-Herriot, Airc. Eng., Vol. II, No. I6, June, I930, p. I33.) (I3 199 Great Britain.)

An account, mainly descriptive," of the two common types of altitude control is given. These are the vacuum type and the variable jet control. Considerations are given for preferring the latter. The plant required for producing artificial altitude conditions is discussed, and a diagram is given illustrating the effect of operating the variable jet control in different ways.

The R.E.F. (l'Orange) Fuel Pump. (L. Hausfelder, Autom. Tech. Zeit., Vol. XXXII, No. 32, 20/1I/29, pp. 726-728.) (8.544/13200 Germany.)

In the R.E.F. fuel pump, as in Acro and Junkers fuel pumps, delivery of fuel is governed by rotation of the fuel pump plunger. The suction valve is incorporated in the fuel plunger and the volumetric efficiency is maintained over a wide range of speed. A series of standard sizes is produced and has found considerable application.

\section{Oil Engines}

The Development of the Junker Diesel Aero Engine. (Gasterstädt Autom. Tech. Zeit., Vol. XXXIII, No. I, 10/1/30, p. 2 (Pt. I), and No. 2, 30/1/30, p. 4 I (Pt. II).) (8.59/1320I Germany.)

The Junker aero engine is an adaptation of their opposed piston commercial engine. Reduction in weight is obtained by the use of light alloys and increased speed. The crankcase housing of the 12 cylinder liners is cast in a single block in silumin. A centrifugal fan is employed for the scavenge air, turbulence being obtained by a spiral arrangement of the inlet ports; with careful dimensioning of the air passage an air pressure as low as $3 \mathrm{lbs}$. per sq. inch is sufficient, in spite of the relatively high engine speed. Two fuel pumps are used per cylinder, half load being obtained by cutting out one pump completely. Four fuel nozzles 
produce the spray in the form of a thin fan. The fuel nozzles are of the open type, and accurate injection timing is ensured by placing the pump close to the nozzles. Jerk injection is employed and the pumps are governed by rotating the plungers. When running light the fuel can be diverted into the suction line. The engine pistons are oil-cooled. Difficulties were experienced with the gear drive between the two crankshafts. A special torsiongraph was designed to investigate this problem, diagrams being taken simultaneously at the four ends of the two crankshafts.

The Effect of the Size of the Pre-Ignition Chamber on the Functioning of a TwoStage Ignition Diesel Engine. (H. Mehlig, Autom. Tech. Zeit., Vol. XXXII, No. 32, 20/11/29, p. 723, and No. 34, 10/12/30; p. 783.) (8.59/1 3202 Germany.)

The mathematical analysis concerns only the compression stroke, and is developed for engines of the Acro Bosch type; where the ignition chamber is placed in the piston. In practice only about one half of the calculated pressure difference between the chamber and the main cylinder is obtained. This diminution is due to heating of the air in the chamber. Machines of different size, but similar design, have similar compression curves provided the piston speed is the same.

The Diesel Engine for Vehicles from the Point of View of Economy. (Wawrziniok, Autom. Tech. Zeit., Vol. XXXIII, No. 17, 20/6/30, pp. 416-420.) (8.59/1 3203 Germany.)

From the tabulated performance figures of the principal continental mobile Diesel engines those using pre-ignition chambers (so called two-stage ignition) work at practically the same mean effective pressure as those with normal pressure air injection. The average weight is about two and a half times that of a carburettor engine of equal horse-power and the space occupied is considerably greater, both involving increased chassis size and weight, These drawbacks off-set the admitted saving in fuel cost.

Present Limits of Performance of Mobile Diesel Engines. (P. H. Schweitzer, Autom. Tech. Zeit., Vol. XXXIII, No. I7, 20/6/30, p. 414-416.) (8.59/1 3204 Germany.)

The moderate practicable speed and the limited mean effective pressure of mobile Diesel engines are the main reasons for a power/weight ratio twice that of the petrol engine. The mean effective pressure can be increased to some extent by modifying the injection nozzles and the shape of the combustion chamber. The speed can be increased only if the injection delay can be reduced, most readily by increasing the compression ratio from $14-1$ to 18 or $20-\mathrm{i}$. The cost of manufacture could be kept down by careful design and mass production,

The Packard Diesel Engine. (Airc. Eng., Vol. II, No. I7, July, I930, p. I63. See abstract No. I3/12395.) 8.59/13205 Great Britain.)

The available technical details are given with suitable comment and performance in comparison with petrol engines.

Recent Developments in Airless Injection of Fuel in Diesel Engines. (Fuel, Vol. IX, No. 3, March, 1930, p. I30.) (8.59/13206 Great Britain.)

Messrs. Sulzer have developed an injection valve fed by pressure from a hydraulic type accumulator with a wider range of size of fuel orifice and of injection pressure than the ordinary jerk pump. The pressure is recorded electrically by changes in contact resistance between the pipe line and an enveloping gauge. 
I,200 h.p. Diesel Locomotive with High Air Pressure Transmission. (Witte and Wagner, Z.V.D.I., Vol. LXXIV, No. Io, 8/3/30, p. 289.) (8.59/13207 Germany.)

The M.A.M. firm has built a six-cylinder single-acting engine with solid injection and a single stage air compressor driven by an extension of the crankshaft. Water injection to the compressor limits the air temperature to about $200^{\circ} \mathrm{C}$. after compression. The water is highly atomised and injected towards the end of the compression stroke through a nozzle, much as in fuel injection. The compressed air is passed through a heater receiving heat from the exhaust, where its temperature is raised to approximately $300^{\circ} \mathrm{C}$, and actuates a piston engine coupled to the driving wheel.

The radiator is placed in front as in motor car practice. The control, entirely by throttling the air supply, is as flexible as for the steam locomotive. The output is 1,200 h.p. at about 450 r.p.m.

Compression Ignition Engines. (A. B. Thiemann, Ill. Flug, Vol. XI, No. IO, Oct., 1929, p. 203.) (8.59/13208 Germany.)

A review is given of the attempts made during and since the war to develop a practicable compression ignition aeroplane engine. Sectional diagrams are given of methods of injection and general arrangement and photographs of various types, including Beardmore, Great Britain; Sunbeam, Great Britain; Junkers, Germany; and Packard, U.S.A.

The Design and Development of an Automatic Injection Valve with an Annular Orifice of Varying Area. (W. F. Joachim, C. W. Hicks and H. H. Foster, N.A.C.A. Report, No. 341, March, 1930.) (8.595/13209 U.S.A.)

From author's summary:-An automatic injection valve giving a finely atomised oil spray of broad cone angle was designed with only six parts-twi concentric nozzle tubes flared at one end, two body parts, and two nuts. The nozzle tubes are provided with seats at the flared ends to form an annular orifice which automatically varies in area with the injection pressure. Adjustment of the nuts determines the valve-opening pressure. High speed engine tests indicate that the time lag of auto-ignition is reduced and the efficient combustion is promoted.

\section{Magneto E.M. Shielding}

Suppressing Ignition Interference. (E. A. Robertson and L. M. Hull, S.A.E., Vol. XXVII, No. I, July, I930, pp. 78-86.) (8.93/13210 U.S.A.)

The question of shielding is discussed and various types of shield are illustrated by photographs.

\section{Bomb Dropping}

Transparency of the Sea from Different Heights. (G. Platania, Not. Tech. Aer., Vol. VI, No. 5, May, 1930.) (9.0/132 I I Italy.)

For observation of submarine objects aircraft have certain advantages over surface vessels, not so much by reason of any greater transparency but by greater range of vision at a favourable angle. Certain measurements of the transparency of the sea were made at Capri, and the results are given in confirmation of the author's views.

Contral of Bombing by Lieut.-Col. Tetu's Method. (Guyomer, Rev. F. Aer., No: 7 , Feb., 1930, pp. I66-185.) (9.5/13212 France.)

An elementary mathematical account is given of the sighting methods, with diagrams illustrating the usual types of error. The use of the recording camera 
for training purposes is discussed. A photograph shows twenty bombs shortly after release from the aircraft.

\section{Materials}

\section{Ferrous Metals}

Transactions of the D.V.L. Session,I7/3/30. (Z.V.D.I., Vol. LXXIV, No. 20, I7/5/30, p. 645.) (Io.0/13213 Germany.)

The report of the society's activities includes :-(I) Paints, dopes, varnishes, etc. ; (2) welding; (3) mechanical vibrations; (4) researches in heat transference; (5) materials; (7) wire cables; (8) timbers, etc.; and thirteen complete and twenty-four incomplete researches. Among the completed researches are the following :-

Fatigue tests on high frequency test machines.

Radio-graphic examination of loads.

Compression and bending tests with jointed struts.

Resonance of timber panels with reference to acoustics of rooms.

Crushing limit and force required in forging various metals at different temperatures.

Heat transference from tubes to highly viscous fluids.

Comparative torsional oscillation for the determination of damping.

Accurate measurements of flow coefficients over a weir.

The Addition of Nickel and Chromium to Cast Iron for Engine Cylinders. (Mahle, Autom. Tech. Zeit., Vol. XXXIII, Part 2, Io/I/30, p. 34.) (Io. I I/I3214 Germany.)

Small additions of nickel to certain types of cast iron (between 2 and 4 per cent.) increase the surface hardness and reduce wear.

Recent Development of High Grade Steel. (P. Goerens, Z.V.D.I., Vol. LXXIV, No. 10, 8/3/30, pp. 297-302.) (10.12/13215 Germany.)

High grade alloy steels are produced by electric arc or by high frequency induction current. The initial difficulties in the manufacture of chrome nickel steels which led to extreme brittleness have been overcome by temperature control and by the addition of small quantities of molybdenum as a stabiliser. To meet. the requirements of modern chemical industries the working temperatures have risen rapidly.

Crucibles will withstand temperatures of over $\mathrm{I}, 000^{\circ} \mathrm{C}$. in corrosive atmospheres. The use of high pressure steam with large superheat has affected turbine blading: The increase in dimensions of electrical machinery imposes increase in size of castings and forgings; and attention to composition has. overcome initial difficulties. Heat resisting properties have been obtained by the diffusion of aluminium into the surface, known as alitisation, akin to cementation of steel. Reference is made to cast or sintered tool steels of high tungsten and. cobalt content.

Value of Deposited Chromium as a Corrosion Preventative. (L. Wright, Jrnl. Soc. Chem. Ind., Vol. XLIX, No. 23, 6/6/30, p. 473.) (10.15/13216. Great Britain.)

To achieve permanence on steel there must be a sound undercoat of nickel at least $\mathrm{r} /$ roooth inch thick. The nickel resists corrosion and the chromium tarnish. With good technique the double coat will give reasonable protection in most circumstances but is not easy to produce with the necessary degree of adhesion. The general tendency to provide chromium plating at low cost without precautions has given the process a bad name. 
Some Outdoor Tests of Protective Painting. (U. R. Evans and S. C. Britton, J. Soc. Chem. Ind., Vol. XLIX, No. I4, 4/4/30, p. I73 T.) (10.15/13217 Great Britain.)

It was found that small differences in the composition of the paint had more influence on its resistance to corrosion than differences in the nature of the steel to be protected. Freshly mixed paint with a minimum quantity of oil and thinner gives the best results. Nitro-cellulose paints give generally bad results and appear sensitive to the presence of rust on the metal before painting. Of red lead, iron oxide and graphite, the first gave generally the best results. If, however, the surface to be painted is already covered with rust the graphite paint is to be advised. The air plays a predominant part, London air being especially harmful.

\section{Light Alloys}

Strength in Shear of Thin Curved Sheets of Alclad. (G. M. Smith, N.A.C.A., Tech. Note, No. 343, June, I930, 35 pp.) (I0.21/13218 U.S.A.)

The size of the test specimens is not stated, but by counting the $\frac{1}{4}$ in. rivet holes in the illustrations and allowing a pitch of $\mathrm{rin}$. the specimens appear to be about $8 \mathrm{in}$. by 24in. They are mounted for the most part on frames with straight 24in. edges and curved $8 \mathrm{in}$. ribs. Four different radii were adopted of approximately $4.3,5.2,6.2$ and 6.9 inches. Four sheet gauges were used, .oro, $.014, .020$ and .032. The method of mounting and testing is described and illustrated by sketches and photographs. The buckling shear loads are plotted against the thickness of the sheet, and give a family of curves, the buckling load increasing with the curvature of the sheet. An empirical formula is given, giving the shear stress at buckling as proportional to the thickness divided by the radius of curvature. The experimental results are plotted showing the shear stress of buckling, a function of the radius over thickness. The experimental points lie fairly well on the hyperbola indicated by the formula.

The results should be useful to designers.

Treatable Aluminium Alloys, Brinnell Hardness, Elastic Limit and Tensile Strength. (P. Melchoir, Z. Metallk., Vol. XXII, No. 5, May, 1930, pp. 175-176.) (10.2101/13219 Germany.)

Linear relations are established between the elastic limit, the ultimate tensile strength and the Brinnell hardness of treatable alloys. The experimental values are plotted and compared with the straight lines given by the linear relations. The agreement is fair.

Treatable Aluminium Alloys. (T. W. Downes, Autom. Ind., Vol. LXII, No. 25, 2 1 $/ 6 / 30$, pp. 944-949.) (10.2101/13220 U.S.A.)

Remarkable improvement of certain cast alloys can be effected by heat treatment. A particular alloy showing ultimate tensile strength 22,000 lbs. per sq. inch and elongation of 3 per cent. in $2 \mathrm{in}$. gave after heat treatment $47,000 \mathrm{lbs}$. per sq. in. ultimate strength and 14.5 per cent. elongation in 2 in. A full technical account is given of the methods of preparing the alloy for casting, the crucibles, frames, temperature control, addition of alloy, stirring, fluxing, etc. The elongation yield point and ultimate strength are shown graphically as functions of time of heat treatment. The results on fifteen different alloys are tabulated numerically. Four micro-photographs show corresponding changes in structure.

The erratic group results indicate that the conditions under which the best. test properties are developed remain somewhat conjectural, 
The Magnesium Industry. (J. A. Gann, Ind. and Eng. Chem., Vol. XXII, No. 7, July, 1930, pp. 694-700.) (10.2102/13221 U.S.A.)

A concise account is given of the occurrence of magnesium in the earth's crust, methods of conmercial production, and consumption in the United States. Since 1915 consumption has increased about tenfold, to 900;000 lbs., and the price per $\mathrm{lb}$. has fallen from $20 /-$ to about $2 /-$ per $\mathrm{lb}$. The resistance of the metal to atmospheric corrosion is considered to be equal to that of other common engineering metals, particularly after eliminating electro-negative heavy metals as impurities. The principal application is in pyrotechnics, but recently its value as a constituent of light alloys, particularly for aeroplane work, has become recognised. The properties of cast and wrought pure magnesium and a 7 per cent. aluminium alloy cast, with and without heat treatment, and wrought, art tabulated. Other tables give comparisons with other metals and alloys, both by sectional area and by weight.

Use of Light Alloys in Air-Cooled Radial Engines. (F. Gosslau, Z. Metallk., Vol. XXI, No. 7 , July, 1930, pp. 224-227.) (10.23/13222 Germany.)

A number of photographs and sectional sketches of types of cylinder are given. The flow of heat is discussed and measured temperature gradients are shown across five sections of four types of cylinder fitted with light alloy cooling fins. A photograph is given of the Siemens radial 600 h.p. engine, and a diagram of performance and fuel consumption.

Attacks of Insects un Metals. (O. Bauer and O. Vollenbruck, A. Metallk., Vol. XXII, No. 7, July, 1930, pp. 230-233.) (10.27/13223 Germany.)

A number of cases are cited from other authors, chiefly with reference to attacks by beetles on leadien pipes and cable coverings. Original observations are given with photographs of the damaged specimens and of the insects.

Lead is by far the commonest object of attack, but specimens of tin bored through are shown.

\section{Timber}

The Artificial Seasoning of Timber. (I. F. Moll, Z.V.D.I., Vol. LXXIV, No. II, I 5/3/30, p. 343.) (10.32/13224 Germany.)

In drying timber circulation of the air round the wood is of extreme importance. The process of drying is largely one of diffusion and the rapidity of drving does not depend on the absolute quaritity of water present, but rather on the distribution of the water on the diffusion velocity curve. To remove the last traces of water requires great vapour pressure differences and consequent risk of fracture. Rapid methods of drying are wasteful of material. To reduce the water content of a 2in. beam, weighing $655 \mathrm{~kg} \cdot / \mathrm{m}^{3}$, from 27 to 8 per cent. requires six days. To dry it in one day, as was American practice till recently, is dangerous.

\section{A Wood-Metal Material. (Instrument World, August, 1930, p. 99.) (10.4/13225 Germany.)}

A new process is described by which it is possible to fill the pores of wood: with metal. The material produced combines the properties of both the wood and the metal. The process consists of plunging the wood, either in a natural or prepared state, into molten metal and then subjecting to pressure. It is claimed that this new material can be machined like ordinary wood, that it takes fire with difficulty, and does not swell from absorption of maisture. 


\section{Ice Formation}

Refrigerated Wind Tunnel Tests of Surface Coatings for Preventing Ice Formation. (M. Knight and W. C. Clay, N.A.C.A. Tech. Note, No. 339, May, 1930.) (10.46/1 3226 U.S.A.)

The conditions of ice formation were reproduced and a number of substances were tested as coatings. The substances were classified as soluble in water and insoluble in water. The latter were found to be ineffective. Positive results are therefore restricted to the soluble compounds. These in turn are divided into soft soluble compounds and hard soluble compounds. The former blew away from the leading edge and did not prevent the growth of ice. The latter, adhering strongly to the surface prevented ice formation within certain temperature limits according to their solubility.

Coatings need be applied only to the leading edge and surface as far back as the maximum co-ordinate.

It is suggested that a continuous supply of liquid compound soluble in water to the leading edge might prove an effective method. A good deal of light is thrown on the mechanism of the formation of ice, and photographs illustrate various stages.

Ice Formation on Wings. (U.S, Air Services, April, 1930, p. 23.) (10.46/1 3227 U.S.A.)

Oil or grease covering is not always effective in preventing ice formation. Heating the wings adds considerable weight and has not yet been tried. At present the pilot should keep clear of air conditions where ice is liable to form. Ice warning indicators are available and should be valuable guides.

\section{Matemials, General, Strength, Etc.}

Studies in Vulcanisation of Rubber. (J. T. Blake, Ind. and Eng. Chem., Vol. XXII, No. 7, July, 1930, pp. 737-77I.) (10.52/13228 U.S.A.)

(i) The heat of vulcanisation of rubber by sulphur has been determined over the whole range of combinations. The formation of hard rubber is strongly exothermic, but soft rubber is formed without heat interchange.

(ii) The vulcanisation of rubber with nitro-compounds is discussed and a physical chemical theory is put forward; soft rubber only is yielded.

(iii) The rates of combination of selenium and rubber have been determined and empirical equations obtained in linear form, giving on integration a logarithmic relation which predicts results hitherto considered anomalous.

(iv) Previous theories of vulcanisation are reviewed and a modified theory proposed. An application is made to the process of reclaiming rubber and explains the progressive deterioration of the reclaimed article.

Stresses in Heavy Helical Springs. (E. Latshaw, Jrnl. of Franklin Inst., Vol. CClX, No. 6, June, 1930, p. 791.) (10.57/13229 U.S.A.)

Improved elementary formula are developed which give approximate stresses. by superposition.

The maximum stress is found at a point inside the material. Consequently signs of latigue may be concealed until failure occurs.

Physics and Metallurgy. (W. Rosenhain, Z. Metallk., Vol. XXII, No. 3, March, 1930, pP. 73-78.) (10.6/13230 Germany.)

The selation of molecular physical theory to the properties of metals is: surveyed and illustrated by typical lattice diagrams. 
Stresses in Ties and Struts Under End Constraint. (W. H. Brooks, Phil. Mag., Vol. VIII, No. 57, March, 1930, p. 426 (Part II), and No. 61, June, 1930, p. 1094 (Part III). Io. $605 / 13^{2} 3^{1}$ Great Britain.)

See also abstract No. I2/1 604 . As for the former problems, differential equations are formed and solved for new problems, and charts are drawn for their determination.

Tests on Short Bolts in Wooden Structural Members. (A. Teichmann and K. Borkmann, L.F.F., Vol. VIII, No. I, 24/5/30, pp. 18-38, I 79th Report of D.V.L.) (10.605/13232 Germany.)

The research is a continuation of the work in L.F.F., Vol. II, 1929, page I 47, and D.V.L. Year Book, 1929, p. I35.

A single bolt with sufficient clearance to avoid friction and so short in relation to its diameter that its deformation is negligible passes through the timber specimen at right angles to the fibres.

The lack of homogeneity in the timber raises a number of problems as to the comparative value of the tests, e.g., the differences between heart and sap wood, between trunk and branch, the effects of the position of the bolt relative to the rings, the influence of the boundary distance, of the width, of the type of loading, of moisture, etc.

The details of the mounting of the tests are fully explained and exhibited in diagrams, and sources of error are discussed. Numerous stress-strain diagrams are reproduced of tests up to rupture, and photographs of ruptured pieces are given.

Mean values of the shearing strength and compression strength "are given for Scotch fir, silver fir, spruce, ash, alder, birch, copper beech, and birch plywood.

Sap wood was from 5-20 per cent. weaker than the heart, and quantitative estimates are given for the effects of the different conditions stated above; in particular an increase of moisture from 12 per cent. to 33 per cent. diminished the strength by about 40 per cent. Eight references are given.

Buckling Strength Under Shear of Sheet Metal with Stiffening Ribs. (C. Schmieden, Z.F.M., .Vol. XXI, No. 3, i4/2/30, pp. 61-65.) (10.605/13233 Germany.)

Cross ribs only are considered in the first place.

Simplifying assumptions are made and the partial differential equation of elastic bending is formed. On the assumption of small deformations the equations become linear and are solved in the usual way. The boundary conditions are introduced and after further approximations numerical solutions are obtained for particular cases. obtained.

For diagonal loads a similar method is followed and analogous results are

Finally the case of both cross and longitudinal stiffeners is worked out with the further modification of the numerical coefficient in the expression for the buckling load. The conditions for mininum material under a given load are worked out numerically.

Advances in Fatigue Limit Research since 1929. (H. F. Moore, Meeting of the American Iron and Steel Institute, Z.F.M., Vol. XXII, No. 2, Feb., 1930, p. 55.) (ro.621/13234 Germany.)

For many working substances there exists an upper load limit below which the specimen will not break for milliards of reversals. Short time methods of fatigue testing have not been found reliable. A method depending on electrical conductivity is considered to be more promising. The term "fatigue " fracture 
is misleading. From the moment of solidification, before external stresses are applied, the metal is internally stressed by the presence of ultra-fine cracks.

\section{Testing Methods, Apparatus and Instruments}

The Wind Tunnel as an Engineering Instrument. (A. L. Klein, S.A.E., Vol. XXVII, No. I, July, 1930, pp. 87-90.) (1 x.16/13235 U.S.A.)

The applications and limitations of the wind tunnel are briefly stated and discussed.

Inspection of Metals and their Alloys. (L. W. Johnson, Jrnl. R. Aer. Soc., Vol. XXXIV, No. 234, June, I930, pp. 44I-494.) (I I.24/1 $3^{2} 3^{6}$ Great Britain.)

The author discusses the whole range of tests methods, and gives tables and graphical charts and photographs of test pieces. The origins of various defects in ingots, forgings and working parts are discussed. The correlation of Brinnell tests with other qualities is considered carefully. Directions are given for pickling and etching specimens of steels and non-ferrous alloys.

Application of X-Rays to the Study of Metals. (J. B. Friauf, Rev. Sci. Insts., Vol. I, No. 7, July, I930, pp. 361-396.) (1 $1.26 / 13^{2} 37$ U.S.A.)

A descriptive and elementary geometrical account is given of the reflection and refraction of $\mathrm{X}$-rays from crystals.

Photographs of reflection and refraction patterns are reproduced. Forty-one references are griven.

New Power Torsionmeter. (Instrument World, Aug., 1930, p. 99.) (11.27/1 $33^{238}$ Great Britain.)

A new apparatus is described for measuring torsion of shafts under load. The principle used is the elongation of a steel thread stretched along the shafting and fixed by two brackets which are themselves fixed to two wrought iron rings on the shafting at a definite distance from each other. The thread is made to vibrate by an electro magnet in the neighbourhood and the vibrations set up an alternating current in another electro magnet. Frequency varies with the variation of length of the thread which is produced by fluctuations in torsion of the shaft. This current actuates a loud speaker telephone at a distant observation station in which a similar system is provided. The thread in this latter system is stretched by a micrometer screw and accordingly its length and load are correctly known.

Airships, Etc.

Some Details of the Next Zeppelin. (Airc. Eng., Vol. II, No. I6, June, 1930, p. I53.) (I 2. 13/13239 Great Britain.)

It is stated that these details were given by Dr. Eckner during his recent visit to London.

Transverse Frames of Rigid Airships. (H. M. Lyon, Jrnl. Royl. Aer. Soc., Vol.

XXXIV, No. 234, June, I930, p. 497.) (1 2.2/13240 Great Britain.)

The methods of calculations were developed by the author when a member of the technical staff at R.A.W., Cardington. A large number of formulæ are worked out for different conditions of loading, the transverse being treated as separate from the longitudinal frame.

Although not a complete solution of the problem the bringing together of a large number of worked out partial problems is useful for the designer. 
Modern Airship Ports. (D. Breithaupt, IIl. Flugwoche, Vol. XI, No. Io, Oct., 1929, Supplement.) (1 2.4/13241 Germany.)

The lay-out of an airship port for modern requirements is discussed. Various suggestions are made for pivoting the whole shed in the direction of the wind. Alternatively a combined system of pivoted, movable and fixed sheds enables the airship after landing in a pivoted shed to be transferred to a fixed one.

Operation and Construction of Kite Balloons. (W. Kamm, L.F.F., Vol. VI, Part 3, 10/2/30, pp. 6r-86.) (12.5/13242 Germany.)

The date of the original paper is $20 / 12 / 2 \mathrm{I}$, but the matter is thought worth publication. References are given to previous work. Formulæ are developed for the attainable height, taking into account wind pressures and giving the drag on the mooring rope at different wind speeds.

Various types are described and numerical values are given from which it appears that the English type possesses considerable advantages. Certain disadvantages are considered and improvements are suggested.

Stability is discussed and diagrams of moments are given for a usual type of mooring. The whole subject is examined numerically, including practical tests of the English type and of a selected German type.

It is concluded that the principles of correct design have been established. Five photographs of the German $\mathrm{K}$ balloon in various attitudes are given.

Comparison berween Riedinger (German) and Caquot (French) Captive Balloons. (Rev. F. Aer.. Feb., 1930, pp. 210,218 .) (1 2.5/13243 France.)

The French Caquot observation balloon has the point of attachment relatively far from the centre of gravity, involving a high incidence in strong winds. The German Riedinger balloon has a better shape and attachment giving less incidence. The rate of hauling down is twice that of the Caquot, and in a high wind the drag on the cable is one quarter.

The First Inflation of the R. 100. (P. L. Teed, Airc. Eng., Vol. II, No. I6, June, r930, p. I35.) (12.6r/13244 Great Britain.)

An account is given of the technical, chemical, thermal, operational, and financial factors entering into the problem of hydrogen production on the large scale required.

Present Position of Helium Supply and Research. (H. Beelitz, Z.F.M., Vol. XXI, No. 5, I4/3/30, pp. Iog-I I5.) (I 2.62/13245 Germany.)

The sources of supply in the United States are described, with statistics of the available quantities.

The possibility of combining power gas and lifting gas in the same hull with a minimum of fire risk is discussed.

The chemical and physical properties of helium are briefly considered.

\section{Wireless}

Japanese Radio-Frequency Standard. (Y. Namba, Proc. Inst. Rad. Eng. (U.S.A.), Vol. XVIII, No. 6, June, I930, p. Ior7.) (13.0/13246 Japan.)

A descriptive account is given of the laboratory equipment whereby a standard frequency of nearly 1,000 cycles per second at $36^{\circ} \mathrm{C}$. was maintained, with an accuracy of a few parts in a million.

Air Transport Communication. (R. L. Jones and F. M. Ryan, Bell Tele. Lab., No. B.478, May, 1930.) (13.1/13247 U.S.A.)

A number of test curves are given of signal strengths against distance, which apparently fall off with height as well as distance. A number of wiring 
diagrams are given for the standard apparatus established in the United States. Photographs are given of assembled apparatus and of the method of using mouth and earpieces.

Radio Facilities for Aircraft Communication. (E. L. Nelson and F. M. Ryan, Bell Tel. Lab., No. B.471, May, 1930.) (13.1/1 3248 U.S.A.)

Photographs are given of sets designed for aircraft communication, with brief specifications, diagrams of connections on aircraft and test curves of signai strengths. Shielding of the ignition system is discussed and illustrated by two photographs. (See also No. 14/12872.)

Meteorological Influences in Reception in Japan. (E. Yokoyama and T. Nakai, Proc. Inst. Rad. Eng. (U.S.A.), Vol. XVIII, No. 6, June, 1930, p. 1075.) (I3. I/13249 Japan.)

Reception at wave lengths of 10,000 to $20,000 \mathrm{~m}$. from distances of 3,000 to I $1,000 \mathrm{~km}$. were studied, and monthly averages were plotted from 1926 to 1928. It is inferred that the field intensity varies inverselv as the atmospheric temperature on the receiving side, not only for monthly averages but for daily variations; but the true meteorological causes and effects are not considered to be established.

Amplification and Rectification of Electron Tubes. (N. Vermes, Ann. d. Phys., Vol. IV, No. 7, May, 1930, p. 943.) (13.1/13250 Germany.)

From author's summary :-Diagrams of the connections of the experimental apparatus are given. The data of the tube are based on determinate steady values. When an additional electromotive force is excited in the grid circuit the data are determined by a new set of steady values. The change in the anode voltage appears as a quadratic function of the additional grid voltage; the coefficient of the linear term is the amplifying factor, the data of the tube and of the external circuit appearing in the expressions. The formulæ give the amplification and rectification, the latter being additive. From the general formulæ for amplification and rectification well-known particular cases are derivable. The formulæ were checked by a series of experiments.

Reflection of Long Electro-Magnetic Waves from the Upper Atmosphere. (D. Burnett, Phil. Mag., Vol. X, No. 62, July, r93o, Pp. I-17.) (13.5/1325 I Great Britain.)

The solution of the problem of the reflexion of long electro-magnetic waves from the upper atmosphere has been solved on the assumptions that the earth is a perfectly conducting sphere and that the concentric spherical surface divides the atmosphere into two parts, each homogeneous. The method is satisfactory for short wave lengths. In the present paper the method is generalised and an exact solution is found in Bessel finctions in a form suitable for computation.

(i) Simultaneous Observations on Downcoming Wireless Waves. (E. V. Appleton and J. A. Ratcliffe, Proc. Roy. Soc., Vol. CXXVIII, No. A.8o7, pp. I 33-1 58.)

(ii) Short Wave Equivalent Height Measurements of the Ionised Regions of the Upper Atmosphere. (E. V. Appleton and A. L. Green, ditto, pp. 159-178.) (13.5/13252 Great Britain.)

(i) Measurements were made on the equivalent height of ionised layers of the atmosphere reflecting signals between 200 and 500 metres wave length over distances of $18 \mathrm{~km}$., $9 \mathrm{I} \mathrm{km}$. and $I_{3} \mathrm{I} \mathrm{km}$. Two reflecting layers were determined at heights of 200 and $110 \mathrm{~km}$. respectively. The lower layer is only effective during daylight. 
(ii) In the second article determinations were made with wave lengths of the order of 100 metres. Results are applied and compared with previous measurements. Generally speaking, the shorter waves penetrated further into the ionised layers before being deflected than longer waves. The variations from night conditions to day conditions and diurnal fluctuations are discussed.

Single and Coupled Circuit Systems. (T. S. Purington, Proc. Inst. Rad. Eng., Vol. XVIII, No. 6, June, I930, p. 983 , p. Io16.) (13.5/13253 U.S.A.)

From author's Summary :-Transmission equations are developed and it is shown that for a desired possible transmission-curve shape, the sum of all decrement coefficients must be a certain amount, readily computable for coupled circuits as well as for single circuits.

Coupled circuit transmission-curve shapes may be developed from singlecircuit curves by a multiplication process as in staggered-cascade amplification, or by a vector difference process, employing two staggered single circuits with opposite couplings from a power source.

Complex networks are handled by transfer equations by which a branch consisting of a voltage source and resistance in series coupled to a network by a transformer device is replaced by an equivalent voltage and impedence within the network.

Theory of the Radiation Coupling of short Wave Aerial Systems. (R. Bechmann, Ann. d. Phys., Vol. IV, No. 7, May, I930, p. 289.) (13.7/13254 Germany.)

From author's summary :-The system consists of an arbitrary arrangement of parallel conductors, some of which are directly excited by an external e.m.f., while the remainder are excited only by radiation coupling. In the mathematical discussion a system of differential equations of the ordinary vibrational type is formed, the number of equations being equal to the number of conductors. Damping is introduced through Planck's frictional force. The induced electrical field between pairs of radiating conductors is derived in closed form from the Hertz vector.

The coupling forces and the Fourier coefficients are calculated from the characteristic functions of the emitters and are explicitly determined for the fundamental period of the emitters.

The solution of the system gives a simple method of calculating the radiating resistance even of complicated systems of antennæ, in particular for projector antennæ as applied in short wave technique. An example is worked out for emitters excited in phase.

An example of an antenna with an unexcited conductor-reflector is discussed. The best distance between antenna and reflector and the maximum radiation in the principal direction are calculated.

Eighteen references are given.

Effect of Rain and Fog on Propagation of Very Short Waves. (J. A. Stratton, Proc. 'Inst. Rad. Eng., Vol. XVIII, No. 6, June, 1930, p. 1064.) (13.7/13255 U.S.A.)

The expression of the Poynting Vector in the radiation field of a scattering particle regarded as a dipole is written down and summed over a unit volume, The polarisation is given by the Lorenz formula. Integrating over unit sphere, the total energy scattered is obtained. On developing the expression numerically it is found that the scattering of waves longer than $5 \mathrm{~cm}$. is negligible. 
Radio-Telephony on Half-Metre Waves. (S. Uda, Proc. Inst. Rad. Eng(U.S.A.), Vol. XVIII, No. 6, June, 1930, p. ro45.) (I3.7/13256 Japan.)

A description is given of a new receiver for waves of 40 to $80 \mathrm{~cm}$., with photographs and diagrams of connections. Characteristic curves are plotted graphically, and in particular, the audibility of directed waves at. 1o $\mathrm{km}$. was tested. A sharp damping with a divergence of a few degree in every plane was obtained.

\section{Photography and Aerial Survey}

Air Photography Surveys. (J. Durward, Jrnl. R. Aer. Soc., Vol. XXXIV, No. 232, April, I930, p. 344.) (14.1/13257 Great Britain.)

A descriptive account is given of the requirements of a photographic survey. Different types of photograph are classified and the difficulties of interpretation are discussed. Flying organisation and ground organisation require the closest attention to achieve results of any value. In particular ground survey parties must prepare the necessary check points for the reduction of photographs. The great advantage of the air photograph is the refinement, which no ground survey could possibly supply.

Aerial Photography. (Aviation, Vol. XXVIII, No. 19, 10/5/30, p. 952.) (I $4.21 / 13258$ U.S.A.)

A long-distance camera developed by the experts of the Air Corps photographic section obtained a photograph of Mount Ranier, I4,500 feet high, at a distance of 270 miles, from an aeroplane at a height of 20,000 feet. The lens, of a deep red colour, acts as a light filter. A specially sensitive film was used.

New Ultra-Speed Kinematograph Camera taking 40,000 Photographs per Second.

(T. Suhara, Aero. Res. Inst., Tokyo, Rept. No. 6o, May, 1930, 15 pp.) (14.6/13259 Japan.)

By means of a rotating mirror, illumination can be interrupted at a much greater frequency than by any type of mechanical shutter.

Sectional sketches are given of two types, one giving 20,000 illuminations per second and the other 40,000 .

Five examples of films are shown :-

A stream of hot air cut by a two-bladed airscrew; frequency 10,0oo per second.

Sound waves in a circular cylindrical shell, source at axis; frequency 40,500 per second.

Sound waves in a circular cylindrical shell, source eccentric; frequency 30,000 per second.

Sound waves in an elliptical cylindrical shell, source at focus; frequency 31,500 per second.

Sound waves in an elliptical cylindrical shell, source not at focus; frequency 40,500 per second.

Determination of the Trajectory of a Target Moving in Space by Means of Askanio Kino-Theodolite. (R. Leonhardt, Z.V.D.I., Vol. LXXIV, No. II, I5/3/3o, pp. 347-349.) (1 4.6/13260 Germany.)

This instrument is intended for precision recording of aircraft motions. The exposure time is of the order of 3/roco sec., five exposures being made per second. The film showing the aircraft gives the azimuth and elevation of the theodolite and the time of each exposure. The combined use on a base line of two instruments; the motion of both films being controlled by a master timing device, gives the trajectory of the aircraft in space. 


\section{Anti-Aircraft Ranging and Gunnery}

A 75-mm. Field Gun. (G. M. Barnes, Army Ord., Vol. X, No. 6o, May-June, 1930, p. 391.) (15.21/13261 U.S.A.)

The trail and mounting are carried by a trailer truck with two pneumatic tyred double wheels; the truck is detachable and the trail spreads out into four separate arms at $90^{\circ}$, when the weapon is ready for service as a field or antiaircraft gun at an elevation of $80^{\circ}$ and a traverse of $30^{\circ}$. Muzzle velocity $2,175 \mathrm{ft}$. per second, maximum range ${ }_{15}, 000$ yards, ${ }_{5}$ lbs. projectile.

Photographs and sketches illustrate the general arrangement.

\section{Parachutes}

Regulations for Parachutes. (Aviation, Vol. XXVIII, No. 25, 21/6/30, p. 1 226.) (16.1 I/13262 U.S.A.)

A summary is given of regulations issued by the Assistant Secretary of Commerce for Aeronautics. Parachutes must satisfy five tests carried out over twenty . drops from an aeroplane in flight.

(I) Time of opening $\quad \ldots \quad \ldots \quad 3$ secs.

Weight of dummy $\ldots . . . \quad$ I 70 lb.

Aeroplane speed ... $\quad \ldots \quad 70$ m.p.h.

Height $\quad \cdots \quad \ldots \quad \ldots \quad 500 \mathrm{ft}$.

12 drops.

(2) With suspension lines twisted.

Time of opening $4^{\frac{1}{2}}$ seconds; other conditions as before.

Five drops.

(3) Weight of dummy ... ... $600 \mathrm{lbs}$.

Speed of aeroplane ... I

Height $\quad \ldots \quad \ldots \quad \ldots \quad 500 \mathrm{ft}$.

(4) Two drops with a man of $I 70$ lbs. weight from a height of 2,000 feet.

(5) One drop from $2,500 \mathrm{ft}$. with dummy i 70 lbs. Rate of descent not to exceed $2 \mathrm{I} \mathrm{ft}$. per second.

Automatic Parachutes. (Flugsport, Vol. XXII, No. 13, 25/6/30, pp. 224-226.) (I6. I I/1 3263 Germany.)

An account is given of the fatal accident to Nehring during a gliding flight, . caused by the breaking of a wing of his high performance glider. His passenger was thrown clear and was saved by the automatically opening parachute. The - occasion is used to advocate the use of parachutes of this type.

\section{Accidents}

Sajety in Flying. (Tech. Aeron., Vol. XXI, No. 104, June, I930, pp. 122-1 28.) (16.2/13264 France.)

The subject is reviewed by the head of the Inspection Department of the French Air Ministry. Accidents during 1928 are tabulated and the causes are analysed.

Aircraft Failures: Influence of Pouer Plant Weight on Aircraft Performance. (M. Schrenk, L.F.F., Vol. VI, No. 4, I4/2/30, pp. 92-96, I5 th Report of D.V.L., read at D.V.L.) (16.2/1 3265 Germany.)

A graphical chart shows the relative number of accidents due to failure of structure, engine, piloting, external influences, faulty maintenance, and a small miscellaneous balance. 
There is a distinct tendency towards an increase in proportion of enginefailures. The relations between performance and power plant weight, structural. weight, aerodynamical qualities, range and loading are briefly discussed by the: author and by a number of members present.

\section{Deck-Landing and Take-Of}

Catapults. (L. D. Webb, Air Services Mag., Vol. XV, No. 7, July, 1930, pp21-26.) (18.4/13266 U.S.A.)

A descriptive account is given of the equipment and operation of catapultsin projecting aircraft from shipboard. Three photographs are given.

Ship to Shore Air Mail Service. (C. H. Gale, Aviation, Vol. XXVIII, No. 22, $3^{\mathrm{I} / 5 / 30}$, p. I084.) (18.4/13267 U.S.A.)

An account is given of the operation of catapult launching of mail-carrying seaplanes from French and German liners.

\section{Considerations Affecting Pilots}

Light Metal Oxygen Bottles for Portable Breathing Apparatus. (Z. Metallk.,. Vol. XXI, No. 7, July, 1930, pp. 235-237.) (19.1 2/1 3268 Germany.)

Official specifications and tests are given along with two photographs of ruptured bottles. Details of dimensions and test results are given in five tables. The question of corrosion is also considered.

Estimations of the Maximum Attainable Muscular Force and Velocity of Application in Aeroplane Controls. (Z.F.M., Vol. XXI. No. 2, 28/1/30, PP. 36-45, I69th Report of D.V.L.) (19.2/13269 Germany.)

The lay-out of the experiments and the experimental equipment are described. Records were made of repeated control efforts exerted by eleven pilots and students of different ages, weights and heights. The numerical results are given in elaborate tables, and are valuable in designing controls for the maximum effort likely to be exerted.

The effects of fatigue are clearly shown.

\section{Miscellaneous Abstracts}

Economics of Air Transport. (A. Koyemann, Luftfahrt, Vol. XXXIV, No. 3, March, I930, p. 83.) (I3270 Germany.)

A scheme of costing formulae is given with numerical values of the details in a particular example. The possibility is discussed of rendering air transport undertakings remunerative.

Air Transport between North and South America. (W. I. VanDusen, Air Services Mag., Vol. XV, No. 7, July, I930, pp. 29-35.) (1327 I U.S.A.)

Some statistical and technical equipment details are given of the air routes. in South America and the connecting air routes with North America, illustrated by a map. Photographs are given of two seaplanes operating between Buenos Ayres and the States.

The Training of Commercial Pilots in Germany. (R. M. Mock, Aviation, Vol. XXVIII, No. 22, 31/5/30, p. I080.) (I3272 U.S.A.)

From among 700 to $\mathrm{I}, 000$ applicants each year 70 to 80 are selected for a preliminary course of four weeks, and a final selection of about twenty-five remain to continue the course. A complete account is given of the equipment: 
and training courses. The losses are given as one seaplane total loss in 600 flying hours, and one land plane lost in 2,000 flying hours. The proportion of minor accidents is much greater with land machines. Some figures of cost are given.

Problems of Arctic Flying. (H. Wilkins, Aviation, Vol. XXVIII, No. 22, 31/5/3o, p. 1076.) (1 3273 U.S.A.)

A descriptive account is given with a number of technical and economic details of problems that arose during various arctic and antarctic expeditions.

Aircraft Materials. (American Society for Testing Materials, Philadelphia.) ( ${ }_{3} 3274$ U.S.A.)

The following papers, prepared for reading at the Thirty-third "Annual Meeting (June, 1930) are printed in the form of a Symposium :-

Personnel of Advisory Committee.

Ferrous metals used in airplane construction. J. B. Johnson.

Structural and engineering light alloys for aircraft. R. L. Templin, F. V. Hartman and E. C. Hartmann.

Strength and characteristics of wood used in aircraft construction. G. W. Trayer.

Aeronautical textiles. W. E. Emley.

Corrosion prevention methods as applied in aircraft construction. H. S. Rawdon.

Notes of aircraft finishes. H. H. Gardner.

Materials of construction in aircraft engines. R. R. Moore.

Failures of aircraft engine parts and causes thereof. T. T. Neill.

Mechanical testing of aircraft materials. J. B. Johnson.

Meta1 joints in aircraft construction. T. Watson Downes.

Procedure control in aircraft welding. H. L. Whittemore, John J. Crowe and $\mathrm{H}$. $\mathrm{H}$. Moss.

X-ray testing of aircraft materials. Ancel St. John.

Photo-elastic studies of aircraft parts. T. H. Frost. 